\title{
Optimal planning and campaign scheduling of biopharmaceutical processes using a continuous-time formulation
}

\author{
Miguel Vieira ${ }^{a}$, Tânia Pinto-Varela ${ }^{a, *}$, Samuel Moniz ${ }^{\mathrm{b}}$, Ana P. Barbosa-Póvoa ${ }^{\mathrm{a}}$, \\ Lazaros G. Papageorgiou ${ }^{\mathrm{C}}$ \\ a CEG-IST, Instituto Superior Técnico, Universidade de Lisboa, Lisboa, Portugal \\ b INESC TEC, Porto, Portugal \\ c Centre for Process Systems Engineering, University College of London, London, UK
}

\section{A R T I C L E I N F O}

\section{Article history:}

Received 30 September 2015

Received in revised form 19 March 2016

Accepted 4 April 2016

Available online 16 April 2016

\section{Keywords:}

Biopharmaceutical plants

Planning and campaign scheduling

Optimisation

Mixed integer linear programming

\begin{abstract}
A B S T R A C T
This work addresses the optimal planning and campaign scheduling of biopharmaceutical manufacturing processes, considering multiple operational characteristics, such as the campaign schedule of batch and/or continuous process steps, multiple intermediate deliveries, sequence dependent changeovers operations, product storage restricted to shelf-life limitations, and the track-control of the production/campaign lots due to regulatory policies. A new mixed integer linear programing (MILP) model, based on a Resource Task Network (RTN) continuous time single-grid formulation, is developed to comprise the integration of all these features. The performance of the model features is discussed with the resolution of a set of industrial problems with different data sets and process layouts, demonstrating the wide application of the proposed formulation. It is also performed a comparison with a related literature model, showing the advantages of the continuous-time approach and the generality of our model for the optimal production management of biopharmaceutical processes.
\end{abstract}

(c) 2016 Elsevier Ltd. All rights reserved.

\section{Introduction}

The competitiveness in current globalised markets requests industrial companies to manage more efficiently the available manufacturing resources, so as to ensure high levels of responsiveness under high production variability. The case of the pharmaceutical industry is a good example on how market is driving the change on product development and manufacturing. This sector is exploring the development of highly effective bioengineered drugs for the treatment of diseases such as cancer, autoimmune disorders, organ transplant rejection, and many other new drugs are in clinical trials. With the number of biologic drugs increasing, manufacturers are being prompted to find flexible, cost-efficient and environmentally feasible solutions for global scales of production. To tackle these challenges, the adoption of decision-support tools has been outspreaded from the management of the research and development (R\&D) drug portfolio to the optimal design/operation of biopharmaceutical facilities (Ramasamy et al., 2014).

In what concerns the operations management, planning and scheduling decision-making has become an essential issue to the majority process industries. The increasing complexity in managing batch/continuous processes caught the interest of the research community to develop efficient modelling approaches to promote operational performance. Several industrial applications of scheduling models have been quite successfully implemented, as stated by Harjunkoski et al. (2014) and Moniz et al. (2014b). Still, despite the major research developments reported in the literature, the implementation of such models to solve real industrial problems often stumbles, in either modelling specific operational requirements or tackling large planning horizons, constrained by the inherent computational complexity. The development of optimisation tools capable to solve real large-scale industrial problems remains a challenge and new formulations for modelling complex process constraints are required, aiming the integration with common decision-making systems. In the particular case of the biopharmaceutical industry, the development of models for production planning and scheduling of biopharmaceutical processes is acknowledged that has been fairly unexplored.

\footnotetext{
* Corresponding author.

E-mail address: tania.pinto.varela@tecnico.ulisboa.pt (T. Pinto-Varela).
} 


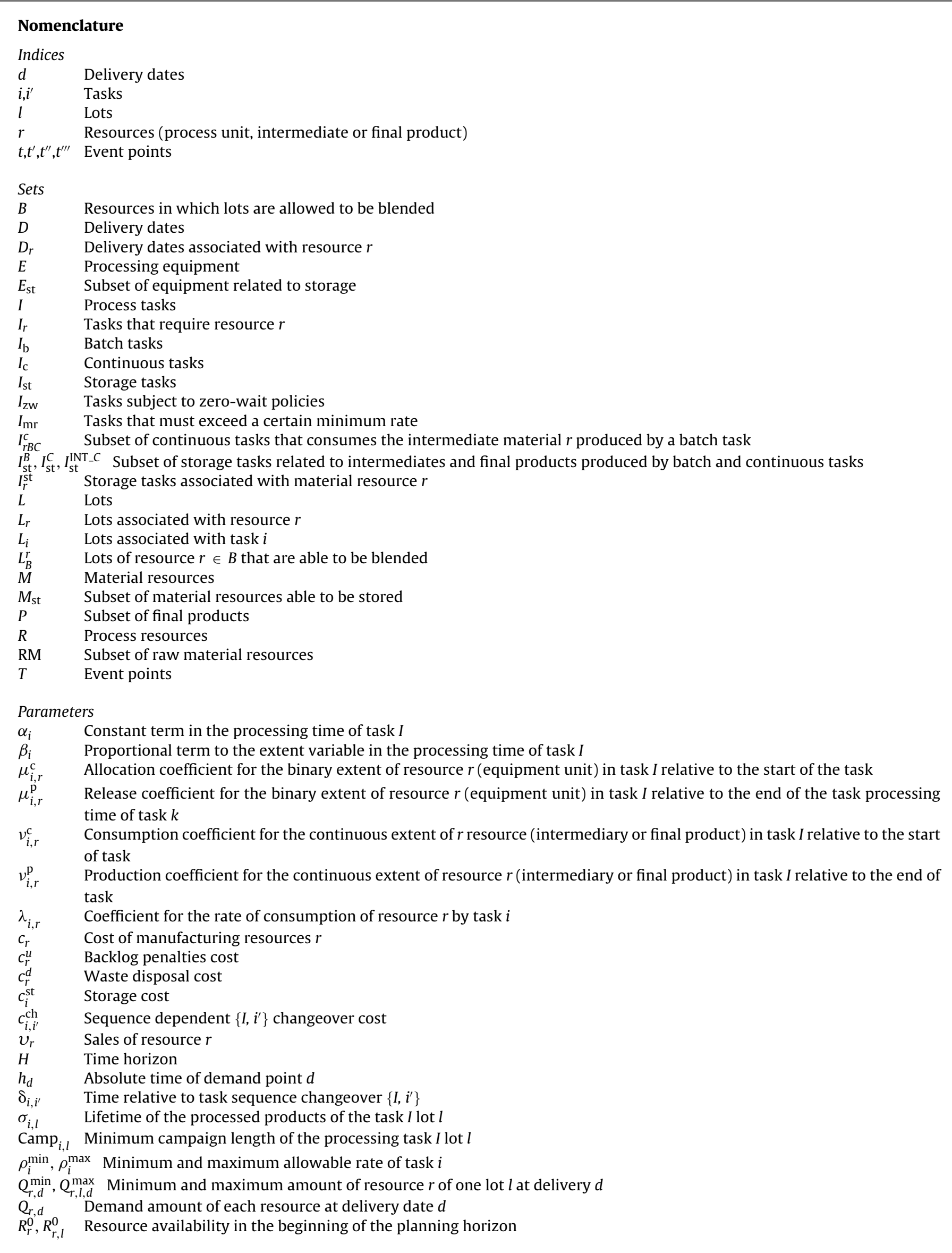




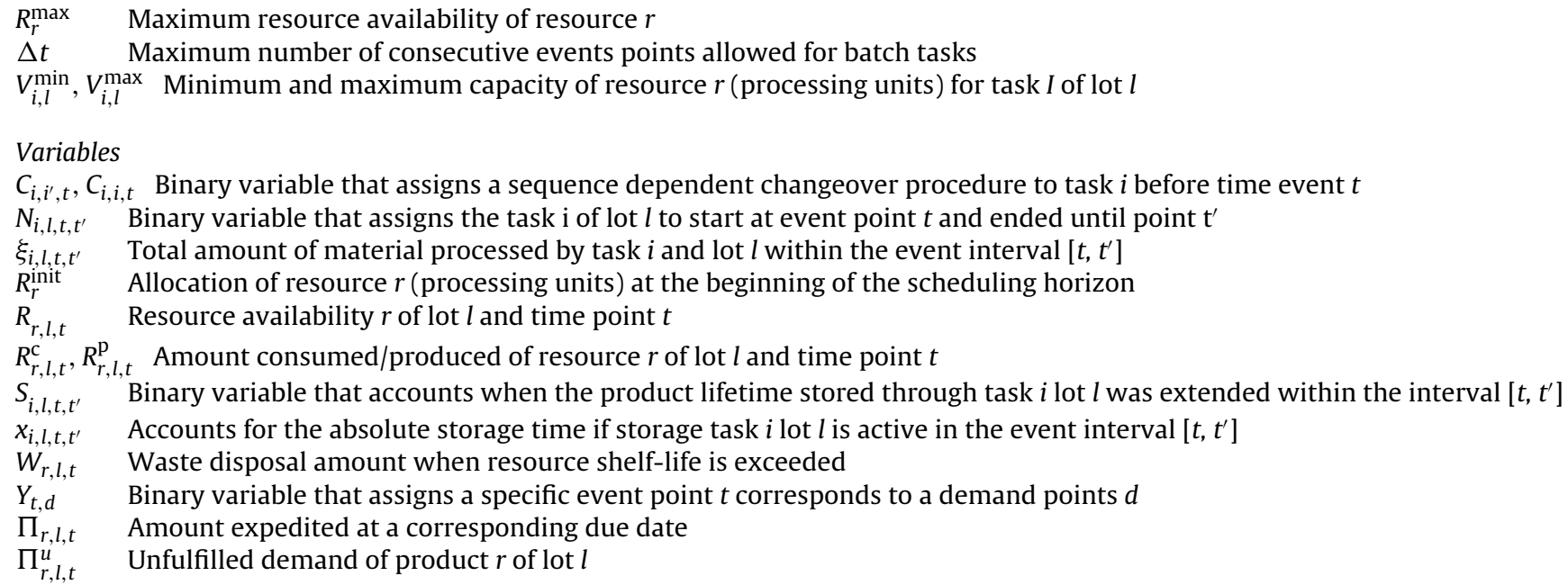

In this paper, we tackle this important problem and propose the development of a campaign planning/scheduling model addressing several operational constraints of the biopharmaceutical processes, such as: (a) batch and continuous tasks; (b) multiple intermediate deliveries, (c) sequence-dependent changeovers; (d) product shelf-life limitations; (e) regulatory track-control of the production/campaign lots. To the best of our knowledge, very little work has addressed the bioprocessing context, notwithstanding the application of some of these operational features to other planning and scheduling problems. A mathematical formulation is proposed to model these operational requirements and two literature-based industrial problems are solved. A results comparison is performed with a literature model considering different time modelling approaches (discrete versus continuous-time), highlighting the performance advantages of the proposed formulation. The remainder of the paper is structured as follows: the next section presents the background in biopharmaceutical planning/scheduling optimisation; Section 3 introduces the problem definition and presents the mathematical model formulation; in Section 4, two problems are presented and discussed regarding its numerical results; finally, Section 5 summarises the main conclusions and future work.

\section{Background}

\section{1. (Bio)Pharmaceutical planning/scheduling optimisation}

Biopharmaceutical drugs refer to complex medicinal biomolecules with pharmacological activity used for therapeutic or in vivo diagnostic purposes. The ability to genetically manipulate (by recombinant DNA or hybridoma technology) highly effective biotherapies such as vaccines, cell or gene therapies, therapeutic proteins hormones, monoclonal antibodies, cytokines and tissue growth factors, has represented a breakthrough in the pharmaceutical industry. The biotech sector has been increasing steadily with a strong pipeline of drugs under clinical trial, representing in 2010 more than $\$ 100$ billion in sales worldwide with over than 200 biologics on the market (Walsh, 2010; Mehta, 2008).

Since the introduction of recombinant human insulin in the 1980s, these molecules are produced by means of genetically engineered biological organisms other than direct extraction from native sources. The manufacturing process is generically composed by two steps: the upstream processes include all tasks associated with cell culture and maintenance of the active biological ingredient, and the downstream processes comprise the chemical/physical operations in the isolation and purification of the drug. The primary fermentation stage consists in the inoculation of the target drug from a cell bank in a growth medium, harvested when reached the optimal concentration. The following purification procedures typically consider filtration of the source material (suitable for blending product variants), followed by chromatography to select the target proteins. The product is then bulked and stabilised with binding agents according to specifications, from where it is lyophilised to remove water and other solvents. This final product can be stored, packaged and distributed to retail or directly to consumers. In each process stage, product quality control tasks are required to assure process licensure by regulatory agencies. The same regulatory control is extended to the entire process components, where any change in plant, equipment or process specifications must be certified for each region of the world where the product is being sold (Leachman et al., 2014).

Most of these manufacturing processes are relatively new and require continuous improvement due to their long lead times, where the main challenge relies in the large scale production of these biomolecules with a stable output quality. For that reason, the mechanisms to produce, purify and preserve the drug have also been subject to research development, along with the therapeutic discoveries. The provision of sufficient output capacity to meet an expected demand, within the patent protection lifespan and without disregarding all the stringent regulations, resumes the production challenge.

The development of planning and scheduling tools is essential in industrial environments to maximise production efficiency and resources assignment. Bioprocess automation has been enhancing the control and monitoring of manufacturing parameters, as reviewed by Junker and Wang (2006), with relevant achievements in applications of process analytical technology (PAT) for quality and performance attributes. But besides the manufacturing optimisation, the operations planning ranges from the portfolio management of biopharmaceutical drugs development to the design optimisation models for specific steps of the production process. It is acknowledged that the 
extended drug development process and the high uncertainty of the drug's clinical success commonly leads to a pipeline of compounds under trial. As example, Rajapakse et al. (2005) developed a prototype decision-making application based on simulation tools, to assist the management of the R\&D portfolio by accessing both the therapeutic drug development activities and its resources flows, and Farid et al. (2007, 2005) presented the SIMBIOPHARMA software tool, able to evaluate manufacturing strategies of drug candidates in terms of cost, time, yield, resource utilisation and risk uncertainty. Whereas addressing some specific aspects of process design, Brunet et al. (2012) addressed the design of upstream/downstream units in a single-product processes with a mixed integer dynamic optimisation and Liu et al. (2015) have proposed significant research work on the optimisation of downstream chromatography sequencing and column sizing strategies. However, it is noticed a relatively small number of research papers addressing the production planning/scheduling of biochemical processes, either encompassing the process performance optimisation as well as operating costs, resource utilisation or uncertainties (Vieira et al., 2015). Lakhdar et al. (2005) proposed a discrete time MILP model for the optimal production and cost effective planning of manufacturing tasks for a medium term horizon of 1-2 year and compared with an industrial rule-based approach. Then, Lakhdar et al. (2007) addressed a multi-objective long term planning horizon and Lakhdar and Papageorgiou (2008) considered the uncertainty in operational parameters, e.g. fermentation titres. More recently, Kabra et al. (2013) developed a continuous-time multi-period scheduling of a multi-stage multi-product process based on State Task Network framework, Liu et al. (2014) extended a production optimisation model to include maintenance planning while considering the performance decay of the chromatography resins, Siganporia et al. (2014) developed a discrete-time model with a rolling time horizon for the capacity planning across multiple biopharmaceutical facilities, and Shaik et al. (2014) proposed two model formulations based on discrete and continuous-time representations for the scheduling operation of biotech batch plants.

Despite the increasing interest within the topics of biopharma, the development of modelling solutions for planning and scheduling problems remains a challenge, as well as exploring the wide intricacy of the operational aspects of these processes. The complexity of planning/scheduling problems in the pharmaceutical sector has been subject to significant attention towards the use of optimisation models and techniques (Shah, 2004). The novelty of these bioprocesses has placed new challenges in modelling research, either addressing the strict process regulatory constraints, products storage shelf-life limitations and biological variability, or campaign basis to comply with product quality requirements and minimise cross-product contamination. Simaria et al. (2012) identified that biopharmaceutical facilities will tend to adopt a smaller scale with multiple bioreactors, able to reduce the capital cost and optimising the number of production batches to match uncertain demand. Traditional batch processing may still remain the predominant approach to manufacturing (Ramasamy et al., 2014), but technological enhancements in continuous processes (e.g. perfusion technique) are showing improved productivities and operational outcomes. Likewise, to comply with process licensure, the option to use typical stainless steel vessels, with required cleaning in-between batches, can be evaluated against the alternative of single-use disposable equipment.

Noteworthy, the general problem of planning and scheduling operations has been gathering extensive research in process industry, with relevance to modelling and optimisation scheduling methodologies as reviewed by Méndez et al. (2006) and Harjunkoski et al. (2014). The approaches based on a unified process representation, both the State-Task Network (STN) and the Resource-Task Network (RTN) proposed by Kondili et al. (1993) and Pantelides (1994) respectively, have proven to be effective in most classes of scheduling problems. As an example of a real pharmaceutical industrial scheduling problem, Moniz et al. (2013) proposed an MILP discrete time formulation based on the RTN framework, considering some production constraints, such as sequence-dependent changeovers, temporary storage in processing units, lots blending/splitting and materials traceability.

The boundaries of planning/scheduling problems are typically associated with the type of decision detail required for a given timehorizon, ranging from several hours/days (short-term scheduling) to several weeks/months (campaign scheduling/mid-term planning). Regarding the time-horizon model representation, two different approaches have been explored: discrete-time and continuous-time. The discrete-time formulations consider the division of the time horizon into equal length intervals, assuming fixed processing times multiple of those intervals, see for instance the recent work by Moniz et al. (2014a), while the continuous-time formulations can be more sensitive to changes in the tasks duration, for example to deal with continuous processes, where the start/duration of the scheduled slots in the time horizon remains a variable. The continuous-time formulations can rely on a single time-grid common to all resources (Maravelias and Grossmann, 2003; Castro, 2010) or multiple time-grids for each resource of the process (Shaik and Floudas, 2008, 2009). However, it is acknowledged that each model approach is strongly determined by the selected problem representation of the material flow and unit specific constraints, which impacts on its complexity and performance.

Considering the characteristics of the planning and campaign scheduling problems in a biopharmaceutical facility, the proposed MILP model is based on the RTN framework using a continuous-time formulation with a single time-grid. The mathematical formulation aims at addressing the main planning/scheduling constrains of these bioprocesses, namely, the schedule of batch and/or continuous process steps, multiple intermediate deliveries, sequence dependent cleaning operations, storage of products regarding shelf-life limitations, and the track-control of the production lots for regulatory policies.

\section{Model characteristics}

\subsection{Problem definition}

This study proposes the development of a continuous-time MILP model, based on the RTN framework, to address the optimal planning of the production and determine for each campaign the schedule with unit-task allocations, the task timings and the flow/store of material through the plant of a biopharmaceutical process. The objective is to maximise the profit by determining the optimal task-unit assignment and sequencing, sequence dependent changeovers, the temporary storage allocation, campaign-lots number and duration/size and eventual blending/splitting requirements, given:

(i) the product recipes in terms of their respective RTN framework;

(ii) the product demands and due dates;

(iii) the characteristics of the processing units; 


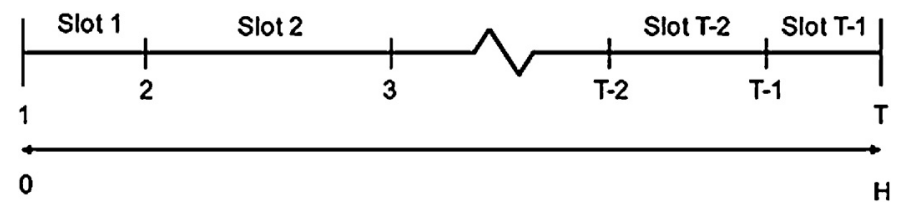

Fig. 1. Single time grid for the continuous-time model.

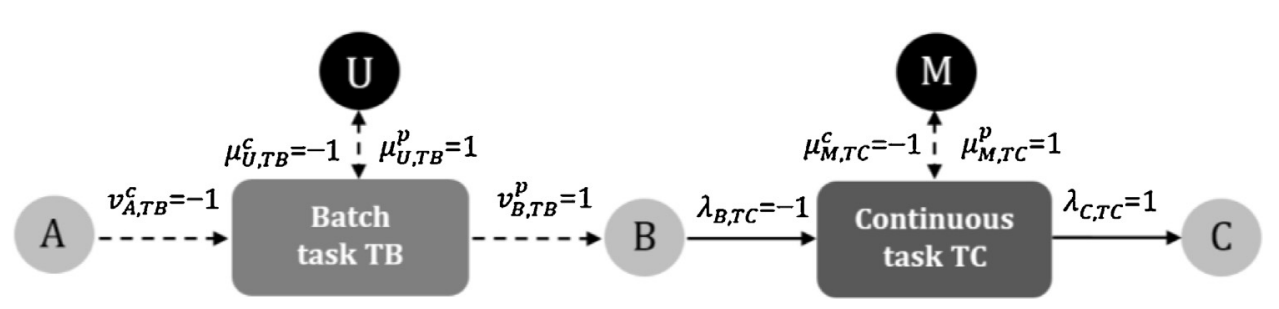

Fig. 2. RTN process representation.

(iv) processing times, operational costs and the task-unit suitability;

(v) the shelf-life storage of intermediaries/products;

(vi) the value of the products;

(vii) and the costs for all materials.

\subsection{Mathematical formulation}

The problem defined above is modelled through a RTN continuous-time formulation based on the model proposed by Castro et al. (2004), which accesses our premise to address both batch and continuous processes. It must be noted that, by process definition, in a batch operation mode the materials are entirely consumed at the start of the respective production task, and the amount produced is made available only at its finish. However, in a continuous operation, a production flow rate is verified along the duration of the task, which allows that sequential continuous tasks can occur simultaneously. The identified features of planning and campaign scheduling problems in biopharmaceutical processes are addressed by extending the baseline formulation with a new set of variables and constraints detailed as follows.

\subsubsection{Resource Task Network framework}

The RTN process framework unifies the model formulation in terms of two sets of entities: tasks and resources. A task is an operation that transforms a set of resources, which includes all entities involved in the process such as materials or processing units. The tasks can interact with resources discretely at its start and finish (batch tasks), and/or continuously at a rate that remains constant throughout its duration (continuous tasks). The initial formulation proposed by Pantelides (1994) considered a discrete-time formulation, dividing the time horizon $H$ into fixed and uniform time intervals. Instead, in a continuous-time formulation the length of each interval is unknown, being more sensitive to small changes in task durations (Schilling and Pantelides, 1996). The continuous-time formulation presented in this paper considers a common time grid to all resources and events taking place in the planning horizon. As shown in Fig. 1, the time horizon $H$ is divided into a given number of slots $(T-1)$, but contrary to its discrete-time formulation, the absolute time of the event point $t$ is determined through variable $T_{t}$.

The RTN continuous-time formulation, as well as its discrete-time counterpart, considers binary $N$ and continuous $\xi$ variables to characterise the event of task $i$ starting at point $t$ and ending at (or before) point $t^{\prime}>t$ (Castro et al., 2004). Moreover, to assure typical regulatory policies of the pharmaceutical processes (Moniz et al., 2013), these variables are now extended to include a lot index $l$, congregate 4 -indices iltt'. The binary variable $N_{i l t t^{\prime}}$ is equal to one if lot $l$ of task $i$ starts at event point $t$ and finish until event point $t^{\prime}$, $\xi_{i, l, t, t^{\prime}}$ gives the lot amount of material processed within the same time slot $\left[t, t^{\prime}\right]$. This modelling feature enhances the ability to trace the schedule of different lots of the same product campaign that, for example, could be blended/splitted during the process. The extent variable of the task for a certain time interval defines the total campaign-lot amount to be produced, suitable to address the size/duration of the campaign according to the requirements of the production plan.

The biopharmaceutical processes can consider either batch and/or continuous tasks throughout its production steps, according to the selection of technological equipment. The amount of each resource produced or consumed is assumed to be proportional to the characteristic variables of the task by a set of structural parameters. The parameters $\mu_{i, r}^{\mathrm{p}}$ and $\mu_{i, r}^{\mathrm{c}}$ associate the discrete interactions with the $N_{i, l, t, t^{\prime}}$ variables, used whenever the amount of resource $r$ produced or consumed is independent of the amount processed, as it is the case of equipment items. For material resources, discrete iterations parameters $v_{i, r}^{\mathrm{p}}$ and $v_{i, r}^{\mathrm{c}}$ links the extent variables $\xi_{i, l, t, t^{\prime}}$ to the amount processed. A task can also interact in a continuous manner with one or more resources for its duration (typically material resources), where parameter $\lambda_{i, r}$ accounts for the rate of generation of the resource associated with the extent variable $\xi_{i, l, t, t^{\prime}}$. As example, Fig. 2 shows a general RTN representation for a process composed by two consecutive tasks. The batch task (TB) consumes material A and produces material B, while the continuous task (TC) consumes material B and produces material C. Moreover, task TB requires the processing unit U and task TC the processing unit M. The dashed lines represent discrete interactions, while solid lines depict continuous interactions (noted that interactions with equipment are, by model definition, always discrete). In each connection the previous parameters are identified, where, for each task, negative values will grant the consumption of the respective resource $r$ on task $i$ for one interval [ $\left.t, t^{\prime}\right]$, whereas positive values denote production. 


\subsubsection{Timing constraints}

To account for the duration of a task $i$, it is assumed that the processing time can be given by a constant $\alpha_{i}$ plus a term proportional $\beta_{i}$ to the amount of material being processed, as $\left(\alpha_{i}+\beta_{i} \xi_{i, l, t, t^{\prime}}\right)$. This allows to represent all types of tasks, for example, either a batch task $I_{\mathrm{b}}$ with a fixed duration (e.g. $\alpha_{i}>0$ and $\beta_{i}=0$ ) or a continuous task $I_{\mathrm{c}}$ with processing rate $\rho_{i}$ (e.g. $\alpha_{i}=0$ and $\beta_{i}=1 / \rho_{i}$ ) with $\rho_{i} \in\left[\rho_{i}^{\text {min }}, \rho_{i}^{\text {max }}\right]$. With the assumption that only one task per lot can be executed at any processing equipment $\left(r \in E \backslash E_{\mathrm{st}}\right)$ at each time interval, Eq. (1) imposes that the difference between the absolute times of two event points $\left[t, t^{\prime}\right]>0$ must be either greater or equal than the processing time of the tasks starting and finishing within the interval. Thereby, the first term is referred to the sum of batch tasks and the second to continuous tasks. Since this formulation allows the relaxation of the duration of the tasks in each time interval, Eq. (2) assures that, if required, time constraints are satisfied for batch tasks subject to zero-wait policies $\left(I_{\mathrm{zw}}\right)$ or for continuous tasks that must exceed a certain minimum rate $\left(I_{\mathrm{mr}}\right)$.

$$
\begin{aligned}
& T_{t^{\prime}}-T_{t} \geq \sum_{i \in I_{\mathrm{b}}} \sum_{l \in L_{i}} \mu_{i, r}^{\mathrm{p}}\left(\alpha_{i} N_{i, l, t, t^{\prime}}+\beta_{i} \xi_{i, l, t, t^{\prime}}\right)+\sum_{i \in I_{\mathrm{c}}} \sum_{l \in L_{i}}\left(\frac{\mu_{i r}^{\mathrm{p}} \xi_{i, l, t, t^{\prime}}}{\rho_{i}^{\max }}\right) \quad \forall r \in E \backslash E_{s t}, t \in T, t^{\prime} \in T, t<t^{\prime}, t \neq|T| \\
& T_{t^{\prime}}-T_{t} \leq H\left(1-\sum_{i \in I_{\mathrm{zw}}} \sum_{l \in L_{i}} \mu_{i, r}^{\mathrm{p}} N_{i, l, t, t^{\prime}}-\sum_{i \in I_{\mathrm{mr}}} \sum_{l \in L_{i}} \mu_{i, r}^{\mathrm{p}} N_{i, l, t, t^{\prime}}\right)+\sum_{i \in I_{\mathrm{zw}}} \sum_{l \in L_{i}} \mu_{i, r}^{\mathrm{p}}\left(\alpha_{i} N_{i, l, t, t^{\prime}}+\beta_{i} \xi_{i, l, t, t^{\prime}}\right)+\sum_{i \in I_{\mathrm{mr}}} \sum_{l \in L_{i}}\left(\frac{\mu_{i, r}^{\mathrm{p}} \xi_{i, l, t, t^{\prime}}}{\rho_{i}^{\mathrm{min}}}\right) \\
& \forall r \in E \backslash E_{s t}, t \in T, t^{\prime} \in T, t<t^{\prime}, t \neq|T|
\end{aligned}
$$

To withhold the combinatorial extent of variables and constraints, it is reasonable to introduce in the formulation a parameter $\Delta t=$ $\left(t^{\prime}-t\right)$ to define the maximum number of consecutive events points allowed for each task to occur. The use of a fixed value for $\Delta t$ is quite reasonable in cases where it is expected that few event points exist between the beginning and end of a task, but this parameter should be evaluated for each problem to not compromise the model feasibility or reach suboptimal solutions. To simplify the model formulation, we will consider a single $\Delta t$ parameter only applied to batch tasks, assuming, without loss of generality, that any instance of tasks performed in a continuous mode can last for only one time interval $[t, t+1]$. Since in each time interval only one task can take place in each equipment resource, the previous general time Eqs. (1) and (2) can be rewritten to consider this $\Delta t$ approach for either batch tasks (Eqs. (3) and (4)) and continuous tasks (Eqs. (5) and (6)). Moreover, each equation considers the additional time related to task changeover procedures $\left(\delta_{i, i^{\prime}}\right)$, to occur within the time interval when changeover/set-up is required to take place in the corresponding unit $\left(C_{i, i^{\prime}, t^{\prime}}=1\right)$.

$$
\begin{aligned}
& T_{t^{\prime}}-T_{t} \geq \sum_{i \in I_{\mathrm{b}}} \mu_{i r}^{\mathrm{p}}\left(\sum_{l \in L_{i}}\left(\alpha_{i} N_{i, l, t, t^{\prime}}+\beta_{i} \xi_{i, l, t, t^{\prime}}\right)+\sum_{i^{\prime} \in I_{\mathrm{b}}} \sum_{t<t^{\prime \prime} \leq t^{\prime}} \delta_{i, i^{\prime}} C_{i, i^{\prime}, t^{\prime}}\right) \quad \forall r \in E \backslash E_{\mathrm{st}}, t \in T, t^{\prime} \in T, t<t^{\prime} \leq \Delta t+t, t \neq|T| \\
& T_{t^{\prime}}-T_{t} \leq H\left(1-\sum_{i \in I_{\mathrm{zw}}} \sum_{l \in L_{i}} \mu_{i, r}^{\mathrm{p}} N_{i, l, t, t^{\prime}}\right)+\sum_{i \in I_{\mathrm{zw}}} \mu_{i, r}^{\mathrm{p}}\left(\sum_{l \in L_{i}}\left(\alpha_{i} N_{i, l, t, t^{\prime}}+\beta_{i} \xi_{i, l, t, t^{\prime}}\right)+\sum_{i^{\prime} \in I_{\mathrm{zw}}} \sum_{t<t^{\prime \prime} \leq t^{\prime}} \delta_{i, i^{\prime}} C_{i, i^{\prime}, t^{\prime}}\right) \\
& \forall r \in E \backslash E_{\mathrm{st}}, t \in T, t^{\prime} \in T, t<t^{\prime} \leq \Delta t+t, t \neq|T|
\end{aligned}
$$$$
T_{t+1}-T_{t} \geq \sum_{i \in I_{\mathrm{c}}} \mu_{i, r}^{\mathrm{p}}\left(\sum_{l \in L_{i}} \frac{\xi_{i, l, t, t+1}}{\rho_{i}^{\max }}+\sum_{i^{\prime} \in I_{\mathrm{c}}} \delta_{i, i^{\prime}} C_{i, i^{\prime}, t+1}\right) \quad \forall r \in E \backslash E_{\mathrm{st}}, t \in T, t \neq|T|
$$$$
T_{t+1}-T_{t} \leq H\left(1-\sum_{i \in I_{\mathrm{mr}}} \sum_{l \in L_{i}} \mu_{i, r}^{\mathrm{p}} N_{i, l, t, t+1}\right)+\sum_{i \in I_{\mathrm{mr}}} \mu_{i, r}^{\mathrm{p}}\left(\sum_{l \in L_{i}} \frac{\xi_{i, l, t, t+1}}{\rho_{i}^{\mathrm{min}}}+\sum_{i^{\prime} \in I_{\mathrm{mr}}} \delta_{i, i^{\prime}} C_{i, i^{\prime}, t+1}\right) \quad \forall r \in E \backslash E_{\mathrm{st}}, t \in T, t \neq|T|
$$

Furthermore, it is considered that during the planning horizon a set of multiple demand points $d \in D$ must be satisfied. A similar approach has been followed by Maravelias and Grossmann (2003). The binary variable $Y_{t, d}$ is defined to identify whether a specific event point $t$ corresponds to a demand points $d$. Here, it is assumed that each event point $t, t \neq 1$, has to be associated with one due date $d$ (Eq. (7)). When those events matches, the absolute time $T_{t}$ must be equal to the specified due time $h_{d}$, which is assured by Eqs. (8) and (9).

$$
\begin{aligned}
& \sum_{\substack{t \in T \\
t \neq 1}} Y_{t, d}=1 \quad \forall d \in D \\
& T_{t} \geq \sum_{d \in D} h_{d} Y_{t, d} \quad \forall t \in T, t \neq 1 \\
& T_{t} \leq \sum_{d \in D} h_{d} Y_{t, d}+H\left(1-\sum_{d \in D} Y_{t, d}\right) \quad \forall t \in T, t \neq 1
\end{aligned}
$$


Finally, Eq. (10) assures that no time events have the same absolute value and these timing variables are bounded by Eqs. (11a) and (11b), considering the time horizon interval given by $[0, H]$.

$$
\begin{aligned}
& T_{t+1}-T_{t} \geq 1 \quad \forall t \in T, t \neq|T| \\
& T_{1}=0 \\
& T_{|T|} \leq H
\end{aligned}
$$

\subsubsection{Resource balance constraints}

The resource balance equation states that the excess amount at a specific event point $t$ is equal to the amount at the previous event point. For $t=1$, this value refers to the initial availability $R_{r, l}^{0}$, adjusted by the amounts discretely or continuously consumed/produced by all tasks starting or ending a time event $t$. Constraints for materials resources (set $M$ ) of lot $l$ (Eqs. (12)-(15)) are modelled separately from equipment units (set $E$ ) (Eq. (16)).

Eq. (12) stresses the general balance for all material resources $r \in M$, where $R_{r, l, t}$ characterises the excess resource $r$ availability of lot $l$ and time point $t$. In addition to the initial or previous term of the balance, $R_{r, l, t}^{\mathrm{p}}$ and $R_{r, l, t}^{\mathrm{c}}$ represents the amount produced and consumed, respectively. The variable $W_{r, l, t}$ is related to the waste disposal amount when resource shelf-life is exceeded and $\Pi_{r, l, t}$ to the amount expedited at a corresponding due date. The variables $R_{r, l, t}^{\mathrm{c}}$ and $\Pi_{r, l, t}$ are considered negative in the balance.

The amount of material produced is formulated through Eq. (13), where the first term is related to batch tasks and the second to continuous tasks that produce resource $r$ of lot $l \in L_{r}$. Likewise, Eqs. (14) and (15) formulate the material consumption. However, the latter equation extends the feature of blending lots of stable intermediaries or products to originate other lots of intermediaries or final products (Moniz et al., 2014a). It addresses the consumption balance for a set $L_{B}^{r}$ of lots of resource $r \in B$ that are able to be blended, allowing the tracking of the blending process.

$$
\begin{aligned}
& R_{r, l, t}=\left.R_{r, l}^{0}\right|_{t=1}+\left.R_{r, l, t-1}\right|_{t>1}+R_{r, l, t}^{\mathrm{p}}+R_{r, l, t}^{\mathrm{c}}-W_{r, l, t}+\Pi_{r, l, t} \quad \forall r \in M, l \in L_{r}, t \in T \\
& R_{r, l, t}^{\mathrm{p}}=\sum_{i \in I_{\mathrm{b}}} \sum_{t^{\prime} \in T} v_{i, r}^{\mathrm{p}} \xi_{i, l, t^{\prime}, t}+\sum_{i \in I_{\mathrm{c}}} \lambda_{i, r} \xi_{i, l, t-1, t} \quad \forall r \in M, l \in L_{r}, t \in T \\
& t-\Delta t \leq t^{\prime}<t \\
& R_{r, l, t}^{\mathrm{c}}=\sum_{i \in I_{\mathrm{b}}} \sum_{t^{\prime} \in T} v_{i, r}^{\mathrm{c}} \xi_{i, l, t, t^{\prime}}+\sum_{i \in I_{\mathrm{c}} \backslash I_{r B C}^{\mathrm{c}}} \lambda_{i, r} \xi_{i, l, t+1, t}+\sum_{i \in I_{r B C}^{\mathrm{c}}} \lambda_{i, r} \xi_{i, l, t, t+1} \quad \forall r \in M \backslash B, l \in L_{r}, t \in T \\
& t<t^{\prime} \leq t+\Delta t \\
& \sum_{l \in L_{B}^{r}} R_{r, l, t}^{\mathrm{c}}=\sum_{l \in L_{B}^{r}}\left(\sum_{\substack { i \in I_{\mathrm{b}} \\
\begin{subarray}{c}{t^{\prime} \in T \\
t<t^{\prime} \leq t+\Delta t{ i \in I _ { \mathrm { b } } \\
\begin{subarray} { c } { t ^ { \prime } \in T \\
t < t ^ { \prime } \leq t + \Delta t } }\end{subarray}} \sum_{i, r}^{\mathrm{c}} \xi_{i, l, t, t^{\prime}}+\sum_{\substack{i \in I_{\mathrm{c}} \backslash I_{r B C}^{\mathrm{c}} \\
t^{\prime}}} \lambda_{i, r} \xi_{i, l, t-1, t}+\sum_{i \in I_{r B C}^{\mathrm{c}}} \lambda_{i, r} \xi_{i, l, t, t+1}\right) \forall r \in B, t \in T
\end{aligned}
$$

As previously mentioned, it is considered that only consecutive continuous tasks can occur simultaneously in the same time schedule $[t, t+1]$ (in different equipment units) and the formulation should restrict the schedule of any other combinations. Albeit, the tests performed to the baseline formulation by Castro et al. (2004) verifies all tasks combinations except one: an additional term is required to assure that when a continuous task consumes the intermediate material $r$ produced by a batch task (subset $I_{r B C}^{\mathrm{c}}$ ), that occurs in different time intervals, which is guaranteed by the last term of Eqs. (14) and (15). To further explain this feature, in Fig. 3 is schematised a generic production process of product $\mathrm{D}$ composed by a set of three tasks: the first as a batch task TB $(1 \times A \rightarrow 1 \times B)$ followed by two continuous steps, TC1 $(1 \times B \rightarrow 1 \times C)$ and TC2 $(1 \times C \rightarrow 0.5 \times D)$. For simplification, lets consider the main balance equations for material resources (Eqs. (12)-(14)), assuming that all tasks can last only a single time interval $(\Delta t=1)$ and disregarding all aspects related to the lot features. Considering two demand dates for product D (50 kg@21 h and $60 \mathrm{~kg} @ 33 \mathrm{~h})$, the Gantt chart shows the sequence of scheduled tasks to fulfill that deliveries $\left(\Pi_{D, l, 3}, \Pi_{D, l, 4}\right)$. But as can be noticed, to accurately calculate the balance for intermediate materials B and C, it cannot be based on the same "consumption" term of the equation, as the original formulation suggests. With this reformulation is guaranteed, through the term applied to the set of tasks $I_{r B C}^{c}$, that if material B is produced (at TB) in interval [ $\left.t-1, t\right]$, it is only consumed (at TC1) in the following interval $[t, t+1]$. In the case of material $\mathrm{C}$, since it is used by two consecutive continuous tasks, its production and consumption can occur on the same time interval $[t-1, t]$.

The resource balance constraints to equipment resources $E$ is presented in Eq. (16). Here, the index $l$ in the balance variable $R_{r, t}$ is dropped since the lot traceability is only required for material resources. The initial terms of Eq. (16) follow the same resource availability concerning the occurrence of batch and/or continuous tasks that take place in the boundaries of the time event. The last term refers to the set of storage tasks of each material resource/lot $\left(i \in I_{s t}\right)$. This equation assumes that all equipment resources are considered individually, 


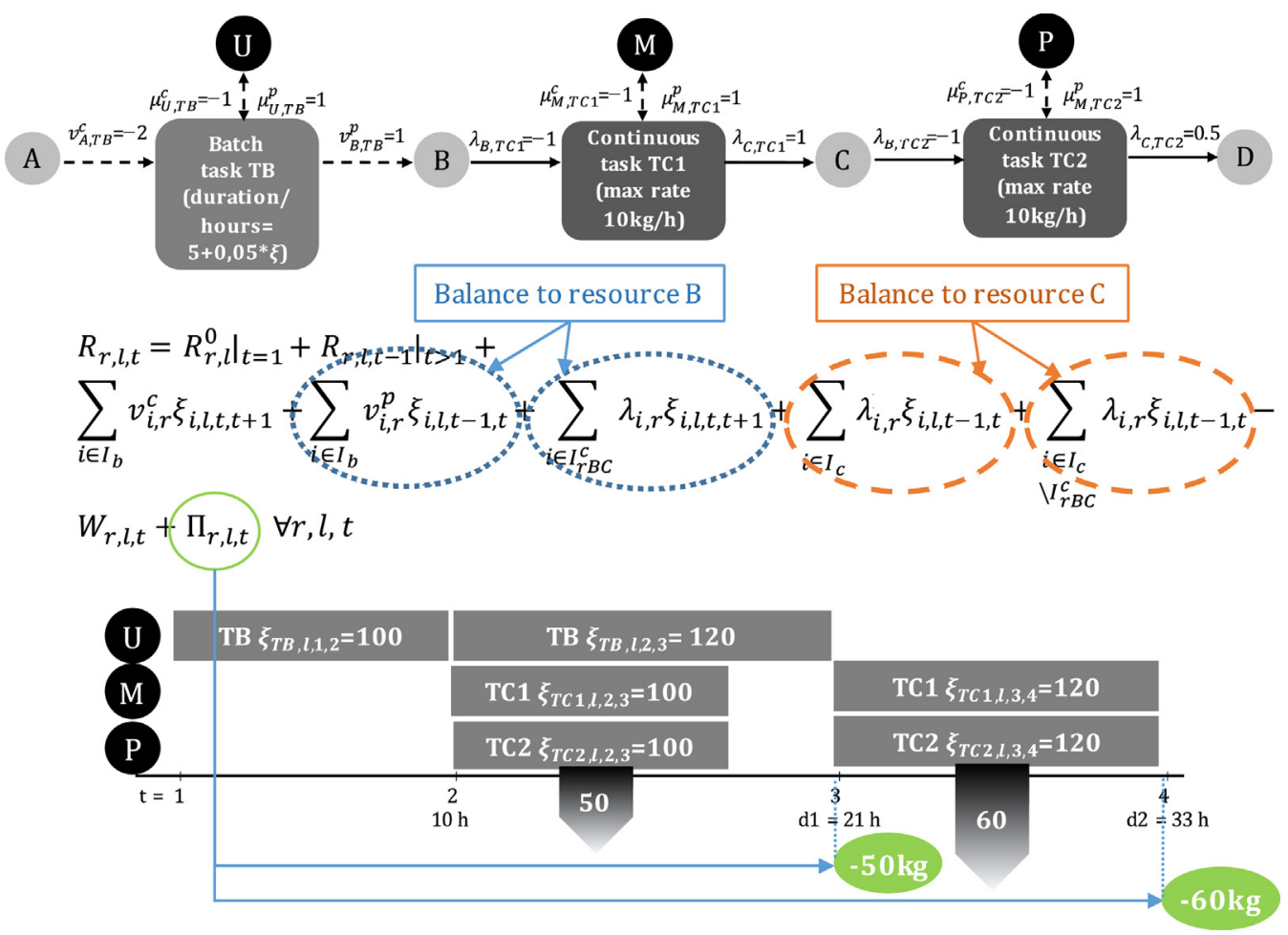

Fig. 3. Representation of process modelling formulation (material resource balance).

with exception of storage tanks $\left(r \in E_{s t}\right)$ which are considered a group of entities available $\left(R_{r}^{\text {init }}>1\right)$, assigned for each product storage when required.

$$
\begin{aligned}
& R_{r, t}=\left.R_{r}^{0}\right|_{(t=1)}+\left.R_{r, t-1}\right|_{t>1}+\sum_{i \in I_{\mathrm{b}}} \sum_{l \in L_{r}}\left(\sum_{\substack{t^{\prime} \in T \\
t-\Delta t \leq t^{\prime}<t}}\left(\mu_{i, r}^{\mathrm{p}} N_{i, l, t^{\prime}, t}\right)+\sum_{\substack{t^{\prime} \in T \\
t<t^{\prime} \leq t+\Delta t}}\left(\mu_{i, r}^{\mathrm{c}} N_{i, l, t, t^{\prime}}\right)\right. \\
& +\sum_{i \in I_{\mathrm{c}}} \sum_{l \in L_{r}}\left(\mu_{i, r}^{\mathrm{p}} N_{i, l, t-1, t}+\mu_{i, r}^{\mathrm{c}} N_{i, l, t, t+1}\right)+\sum_{i \in I_{s t} l \in L_{r}}\left(\mu_{i, r}^{\mathrm{p}} N_{i, l, t-1, t}+\mu_{i, r}^{\mathrm{c}} N_{i, l, t, t+1}\right)
\end{aligned} \quad \forall r \in E, t \in T
$$

Eq. (17) performs the initial assignment of the equipment units $E$, considering processing and storage units, and Eq. (18) bounds the allowed resource availabilities. Eq. (19) guarantees that, when applied, no material resource other than the raw materials (RM) is allowed be stored at the last event of the time horizon. This restriction is particularly useful to access the case that products/by-products cannot be stored beyond the planning horizon due to shelf-life restrains.

$$
\begin{aligned}
& R_{r}^{0} \leq R_{r}^{\text {init }} \quad \forall r \in E \\
& 0 \leq \sum_{l \in L_{r}} R_{r, l, t} \leq R_{r}^{\max } \quad \forall r \in M, t \in H \\
& \sum_{r \in M \backslash \operatorname{RM} l \in L_{r}} \sum_{r, l, t} R_{l}=0 \quad \forall t=|T|
\end{aligned}
$$

\subsubsection{Lot constraints}

According to Moniz et al. (2013), a distinction must be made in the formulation of lots and task-batches. Lots characterise the amount of stable intermediate or final product produced throughout a known set of tasks executed in a known production sequence or recipe. Task-batches are related to the amount of material produced by each task that is limited by the capacity of the processing unit, executing part of the production of a lot. In this way, the formulation addresses the ability to trace the proportions/quantities of all products lots in the production schedule, allowing the record of the processing of a certain lot (or a lot blend/split, if allowed) through the task-batching of raw materials, intermediate and final products. 
Regarding the lot traceability of the produced materials, two additional constrains are considered to enhance the model features. Eqs. (20) and (21) states that, for either batch or continuous tasks, respectively, lot $l$ is only executed if the lot $l-1$ was already assigned, in a previous time interval, to a task that can produce the same material resource (first subtracting term), or up to the same interval but in an alternative equipment unit (second subtracting term). Eq. (22) allows that, if required, lot $l$ of a material resource is never repeated during the planning horizon, which, when no limits are set to a predefined number of lots, allows the determination of the total number of lots required.

$$
\begin{aligned}
& \begin{array}{l}
v_{i, r}^{\mathrm{p}} N_{i, l, t, t^{\prime}}-\sum_{t^{\prime \prime} \in T} \sum_{t^{\prime \prime \prime} \in T} v_{i, r}^{\mathrm{p}} N_{i, l-1, t^{\prime \prime \prime}, t^{\prime \prime}}-\sum_{i^{\prime} \in I_{\mathrm{b}}} \sum_{t^{\prime \prime} \in T} \sum_{t^{\prime \prime \prime} \in T} \\
t_{i, r}^{\mathrm{p}} N_{i^{\prime}, l-1, t^{\prime \prime \prime}, t^{\prime \prime} \leq 0} \quad i^{\prime} \neq i \quad t^{\prime \prime} \leq t^{\prime \prime}-\Delta t \leq t^{\prime \prime \prime}<t^{\prime \prime}-\Delta t \leq t^{\prime \prime \prime}<t^{\prime \prime} \\
\quad \forall r \in M \backslash \mathrm{RM}, i \in I_{\mathrm{b}}, l \in L_{r}, l>1, t \in T, t^{\prime} \in T, t<t^{\prime} \leq t+\Delta t, t \neq|T|
\end{array} \\
& \lambda_{i, r} N_{i, l, t, t+1}-\sum_{t^{\prime} \in T} \lambda_{i, r} N_{i, l-1, t^{\prime}-1, t^{\prime}}-\sum_{i^{\prime} \in I_{\mathrm{C}}} \sum_{t^{\prime} \in T} \\
& t^{\prime} \leq t \quad i^{\prime} \neq i \quad t^{\prime} \leq t+1 \\
& \lambda_{i, r} N_{i^{\prime}, l-1, t^{\prime}-1, t^{\prime}} \leq 0 \quad \forall r \in M \backslash \mathrm{RM}, i \in I_{\mathrm{c}}, l \in L_{r}, l>1, t \in T, t \neq|T|
\end{aligned}
$$

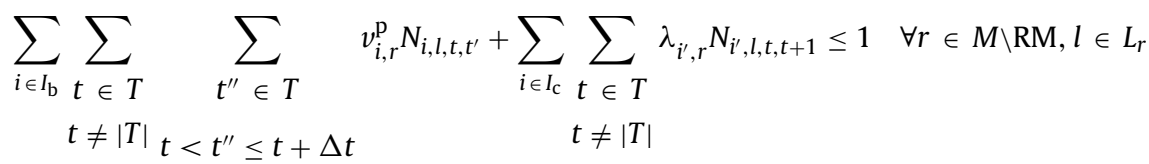

\subsubsection{Multiple deliveries constraints}

The multiple deliveries feature is modelled through Eqs. (23a)-(25). Eq. (23a) defines the multiple product/lot deliveries trough variable $\Pi_{r, l, t}$, with a set of due dates $d \in D$ and products $P$. The amount of resource $r$ of one lot $l$ at due date $d$ can be bounded by minimum $Q_{r, l, d}^{\text {min }}$ and maximum quantities $Q_{r, l, d}^{\max }$, while in each due date the unfulfilled minimum demand of product $r$ of lot $l$ is given by $\Pi_{r, l, t}^{u}$. Considering that, in our approach, the total number of lots $l$ to schedule can be defined as an output solution, Eq. (23b) accesses the same balance assuming a minimum demand profile for single product (combining all lots) per due date, $Q_{r, d}$. The formulation also allows that a delivery could occur in any time event of the planning horizon, besides the predefined due dates. Therefore, Eq. (24) guarantees that no early deliveries are allowed, as well as that the total demand of each product $P$ is not exceeded. Finally, Eq. (25) assures that no deliveries exist for other resources than products $P$.

$$
\begin{aligned}
& \sum_{d \in D_{r}}\left(Y_{t, d} \mathrm{Q}_{r, l, d}^{\min }\right)-\Pi_{r, l, t}^{u} \leq\left(-\Pi_{r, l, t}\right) \leq \sum_{d \in D_{r}}\left(Y_{t, d} \mathrm{Q}_{r, l, d}^{\max }\right) \quad \forall r \in P, l \in L_{r}, t \in T, t>1 \\
& \sum_{d \in D_{r}}\left(Y_{t, d} \mathrm{Q}_{r, d}\right)-\sum_{l \in L_{r}} \Pi_{r, l, t}^{u} \leq \sum_{l \in L_{r}}\left(-\Pi_{r, l, t}\right)-\sum_{l \in L_{r}} \Pi_{r, l, t-1}^{u} \forall r \in P, t \in T, t>1 \\
& \sum_{l \in L_{r}}\left(-\Pi_{r, l, t}\right) \leq \sum_{t^{\prime} \in T^{\prime}} \sum_{d \in D_{r}}\left(Y_{t^{\prime}, d} \mathrm{Q}_{r, d}\right)-\sum_{t^{\prime} \in T} \sum_{l \in L_{r}}\left(-\Pi_{r, l, t^{\prime}}\right) \quad \forall r \in P, t \in T, t>1 \\
& \Pi_{r, l, t} \leq t<\forall \\
& \Pi^{\prime}<t \in M / P, l \in L_{r}, t \in T
\end{aligned}
$$

\subsubsection{Operational constraints}

Assuming that each task can be performed in a single processing unit, Eq. (26) accounts for equipment capacity restrains of batch tasks $\left(V_{i, l}^{\min }\right.$ and $\left.V_{i, l}^{\max }\right)$. For continuous tasks, the boundaries are related to the processing rate and length of the interval (Eq. (27)). In this case, the lower limit is defined by the minimum campaign length of the processing task $i$, set by parameter Camp $p_{i, l}$, and the upper limit to the lifetime of the processed products at the same tasks $\sigma_{i, l}$. This last term reinforces that the product shelf life will never be exceeded during one single continuous task. If required, the same principle can be followed for a batch task by assuming a maximum capacity of the equipment suitable to comply with lifetime of processed materials.

$$
\begin{aligned}
& V_{i, l}^{\min } N_{i, l, t, t^{\prime}} \leq \xi_{i, l, t, t^{\prime}} \leq V_{i, l}^{\max } N_{i, l, t, t^{\prime}} \quad \forall i \in I_{\mathrm{b}}, l \in L_{i}, t \in T, t^{\prime} \in T, t<t^{\prime}<t+\Delta t, t \neq|T| \\
& \mathrm{Camp}_{i, l} \rho_{i}^{\max ^{2}} N_{i, l, t, t+1} \leq \xi_{i, l, t, t^{\prime}} \leq \sigma_{i, l} \rho_{i}^{\max } N_{i, l, t, t+1} \quad \forall i \in I_{\mathrm{c}}, l \in L_{i}, t \in T, t \neq|T|
\end{aligned}
$$




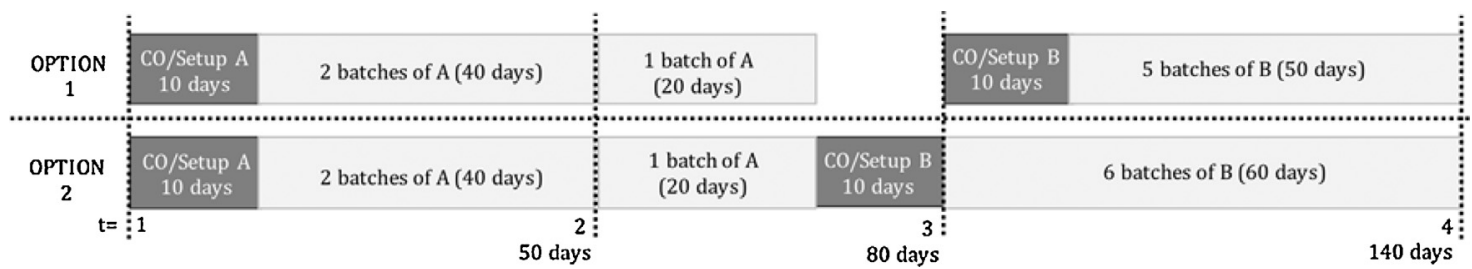

Fig. 4. Changeover tasks allocation options for a production case $[A+B]$.

\subsubsection{Sequence dependent changeover constraints}

The production schedule should also address the required cleaning procedures based on sequence dependent changeovers, considered in our formulation as an autonomous task. In biopharmaceutical processes the changeover task can usually include, besides the cleaning time, any setup time related to process start-up of the following production. For example, considering two consecutive tasks $\left\{i, i^{\prime}\right\}$ of intermediaries products at the time event $t$, if the task $i^{\prime}$ processes a different product than $i$, it is required an intermediate changeover of the shared processing unit $\left(r \in E \backslash E_{s t}\right)$ to occur before the beginning of task $i^{\prime}$ with a specified duration $\delta_{i, i^{\prime}}$. To avoid the increase in the number of scheduled time events, this task is implicitly allocated to the duration of one time interval in the boundary of $t$ where the changeover is required. The novelty presented relies in the flexibility of the allocation to the previous time interval, assuming its performed immediately before $t$, or starting at the beginning of the following interval. As example, Fig. 4 shows the two schedule possibilities for a general case of two products, A and B, able to be produced in the same unit, allowing the increase of the production output of B depending in the allocation of the required changeover task. This flexibility potentiates the objective function results and is particular relevant in single-time grid horizon formulations. Therefore, in Eqs. (28) and (29), a binary variable $C_{i, i^{\prime}, t}$ is introduced to control the sequence of tasks $i \neq i^{\prime}$ and allocation of the require intermediate changeover in the shared equipment, respectively for either batch or continuous task. The same variable is also required to associate a cost to these operations, further penalised in the objective function. However, this case is only verified for consecutive tasks in a time event, which implies to consider whenever empty time intervals exist in between two events $\left(t^{\prime}>t\right)$, adding a new term to Eqs. (30) and (31) to access the changeover time in the boundaries of $t^{\prime}$. Likewise, Eqs. (32) and (33) address the set-up requirements for the first scheduled task on each equipment with the binary variable $C_{i, i, t}$. To avoid suboptimal solutions, Eq. (34) reinforces that in each time interval only one cleaning task takes place per equipment resource.

$$
\begin{gathered}
\sum_{l \in L_{i}} \sum_{t^{\prime} \in T} \mu_{i, r}^{\mathrm{p}} N_{i, l, t^{\prime}, t}+\sum_{l \in L_{i^{\prime}}} \sum_{t^{\prime} \in T} \mu_{i^{\prime}, r}^{\mathrm{p}} N_{i^{\prime}, l, t, t^{\prime}} \leq 1+\mu_{i, r}^{\mathrm{p}} C_{i, i^{\prime}, t}+\mu_{i, r}^{\mathrm{p}} C_{i, i^{\prime}, t+1} \\
t-\Delta t \leq t^{\prime}<t \quad t<t^{\prime} \leq t+\Delta t \\
\forall r \in E \backslash E_{\mathrm{st}}, i \in I_{\mathrm{b}}, i^{\prime} \in I_{b}, i^{\prime} \neq i, t \in T, t>1, t \neq|T|
\end{gathered}
$$

$$
\sum_{l \in L_{i}} \mu_{i, r}^{\mathrm{p}} N_{i, l, t-1, t}+\sum_{l \in L_{i^{\prime}}} \mu_{i^{\prime}, r}^{\mathrm{p}} N_{i^{\prime}, l, t, t+1} \leq 1+\mu_{i, r}^{\mathrm{p}} C_{i, i^{\prime}, t}+\mu_{i, r}^{\mathrm{p}} C_{i, i^{\prime}, t+1} \quad \forall r \in E \backslash E_{\mathrm{st}}, i \in I_{\mathrm{c}}, i^{\prime} \in I_{\mathrm{c}}, i^{\prime} \neq i, t \in T, t>1, t \neq|T|
$$

$$
\begin{aligned}
& \sum_{l \in L_{i}} \sum_{t^{\prime \prime} \in T} \mu_{i, r}^{\mathrm{p}} N_{i, l, t^{\prime \prime}, t}+\sum_{l \in L_{i^{\prime}}} \sum_{t^{\prime \prime} \in T} \mu_{i^{\prime}, r}^{\mathrm{p}} N_{i^{\prime}, l, t^{\prime}, t^{\prime \prime}}-\sum_{i^{\prime \prime} \in I_{\mathrm{b}}} \sum_{l \in L_{i^{\prime \prime}}} \sum_{t^{\prime \prime} \in T} \sum_{t^{\prime \prime \prime} \in T} \\
& t-\Delta t \leq t^{\prime \prime}<t \quad t \leq t^{\prime \prime}<t^{\prime} t^{\prime \prime}<t^{\prime \prime \prime} \leq t^{\prime \prime}+\Delta t \\
& \mu_{i^{\prime \prime}, r^{\prime}}^{\mathrm{p}} N_{i^{\prime \prime}, l, t^{\prime \prime}, t^{\prime \prime \prime} \leq 1+t^{\prime \prime} \leq t^{\prime}+\Delta t} \\
& \quad \forall r \in E \backslash E_{\mathrm{st}}, i \in I_{\mathrm{b}}, i^{\prime} \in I_{\mathrm{b}}, i^{\prime} \neq i, t^{\prime}+\mu_{i, r}^{\mathrm{p}} C_{i, i^{\prime}, t^{\prime}+1} \quad \forall, t \in t^{\prime} \in T, t>1, t^{\prime}>t, t \neq|T|, t^{\prime} \neq|T|
\end{aligned}
$$

$$
\begin{aligned}
& \sum_{l \in L_{i}} \mu_{i, r}^{\mathrm{p}} N_{i, l, t-1, t}+\sum_{l \in L_{i^{\prime}}} \mu_{i^{\prime}, r}^{\mathrm{p}} N_{i^{\prime}, l, t^{\prime}, t^{\prime}+1}-\sum_{i^{\prime \prime} \in I_{\mathrm{c}} l \in L_{i^{\prime \prime}}} \sum_{\substack{t^{\prime \prime \prime} \in T \\
t \leq t^{\prime \prime}<t^{\prime}}} \sum_{\mu_{i^{\prime \prime}, r}^{\mathrm{p}} N_{i^{\prime \prime}, l, t^{\prime \prime}, t^{\prime \prime}+1} \leq 1+\mu_{i, r}^{\mathrm{p}} C_{i, i^{\prime}, t^{\prime}}+\mu_{i, r}^{\mathrm{p}} C_{i, i^{\prime}, t^{\prime}+1} \quad \forall r \in E \backslash E_{\mathrm{st}}, i \in I_{\mathrm{c}}, i^{\prime} \in I_{\mathrm{c}}, i^{\prime} \neq i, t \in T, t^{\prime} \in T, t>1, t^{\prime}>t, t \neq|T|, t^{\prime} \neq|T|}
\end{aligned}
$$




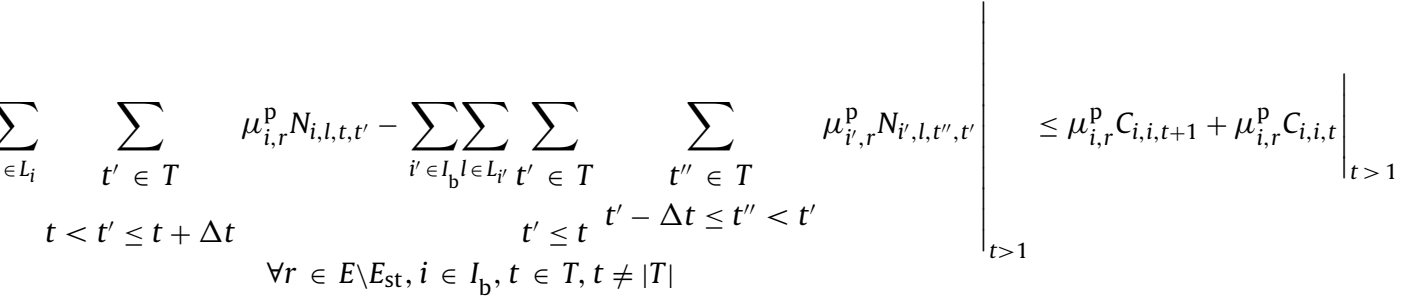

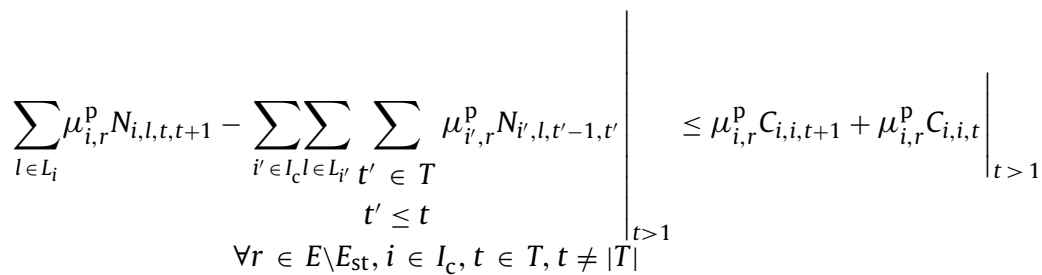

$$
\begin{aligned}
& \sum_{i \in I_{\mathrm{b}} \cup I_{\mathrm{c}} i^{\prime}} \sum_{\in I_{\mathrm{b}} \cup I_{\mathrm{c}}} \mu_{i, r}^{\mathrm{p}} C_{i, i^{\prime}, t} \leq 1 \quad \forall r \in E \backslash E_{\mathrm{st}}, t \in T, t>1, t \neq|T| \\
& i^{\prime} \neq i
\end{aligned}
$$

\subsubsection{Storage and shelf-life constraints}

Considering a set of storage tasks for each intermediaries and final products $I_{\mathrm{st}}=I_{\mathrm{st}}^{B} \cup I_{\mathrm{st}}^{C}$ and a set of storage equipment resources $r \in E_{\mathrm{st}}$, the model should constraint the stored products to shelf-life time restrains. Shelf-life must be considered as the maximum lifetime a product/by-product is able to be stored $\left(\sigma_{i, l}\right)$, sending to waste disposal the respective amounts when this parameter is exceed. Eqs. (35)-(37) control the activation of a storage task in the boundary intervals if there is an excess amount at event point $t$ of the material resource $r$ of lot $l$. Due to the different processing mode of tasks, it is considered that for materials produced by batch tasks, the storage task $I_{\mathrm{st}}^{B}$ must be activate only to the ensuing interval $[t, t+1]$. Instead, the storage of materials produced by continuous tasks, $I_{\mathrm{st}}^{C}$, must be activate on both intervals, $[t-1, t]$ and $[t, t+1]$, since it is assumed that the material is processed continuously from the start of the interval. Additionally, in the case of intermediaries consumed by continuous tasks, the storage task $I_{\mathrm{st}}^{\text {INT_C }}$ task must be active on [ $t+1$, $t+2]$.

$$
\begin{aligned}
& V_{i, l}^{\min } N_{i, l, t, t+1} \leq \sum_{r \in I_{r}^{s t}} R_{r, l, t} \leq V_{i, l}^{\max } N_{i, l, t, t+1} \quad \forall i \in I_{\mathrm{st}}^{B} \cup I_{\mathrm{st}}^{C}, l \in L_{i}, t \in T, t \neq|T| \\
& V_{i, l}^{\min } N_{i, l, t-1, t} \leq \sum_{r \in I_{r}^{\mathrm{st}}} R_{r, l, t} \leq V_{i, l}^{\max } N_{i, l, t-1, t} \quad \forall i \in I_{\mathrm{st}}^{C}, l \in L_{i}, t \in T, t \neq 1 \\
& V_{i, l}^{\min } N_{i, l, t+1, t+2} \leq \sum_{r \in I_{r}^{\mathrm{st}}} R_{r, l, t} \leq V_{i, l}^{\max } N_{i, l, t+1, t+2} \quad \forall i \in I_{\mathrm{st}}^{\mathrm{INT}}, l \in L_{i}, t \in T, t \neq 1
\end{aligned}
$$

To accurately control the shelf-life of stored materials, and since each storage task $\left(i \in I_{\mathrm{st}}\right)$ is activated for the entire time interval, the variable $x_{i, l, t, t^{\prime}}$ is introduced to control the storage time of the corresponding material resource $r$ of lot $l$. As example, the variable $x_{i, l, t, t+1}$ should account as storage time the value of the time period [ $t, t+1]$, given by $\left(T_{t+1}-T_{t}\right)$, only if the storage task is active in that interval, $N_{i l t(t+1)}=1$, otherwise is zero. Therefore, since $\left(T_{t+1}-T_{t}\right)>0, \forall t \in T$, the master constraint could be given by the multiplication of these two variables, $x_{i l t(t+1)} \equiv N_{i l t(t+1)} \times\left(T_{t+1}-T_{t}\right)$, however generating a nonlinear function. Assessing the singularity of the MILP model, Eqs. (38)-(40) formulate the linearization of this proposition for the interval $\left[t, t^{\prime}\right]$.

$$
\begin{aligned}
& x_{i, l, t, t^{\prime}}-H \sum_{\substack{t^{\prime \prime} \in T \\
t \leq t^{\prime \prime}<t^{\prime}}} N_{i, l, t^{\prime \prime}, t^{\prime \prime}+1} \leq 0 \quad \forall i \in I_{\mathrm{st}}, l \in L_{i}, t \in T, t^{\prime} \in T, t^{\prime}>t, t \neq|T| \\
& x_{i, l, t, t^{\prime}} \leq\left(T_{t^{\prime}}-T_{t}\right) \quad \forall i \in I_{\mathrm{st}}, l \in L_{i}, t \in T, t^{\prime} \in T, t^{\prime}>t, t \neq|T| \\
& x_{i, l, t, t^{\prime}} \geq\left(T_{t^{\prime}}-T_{t}\right)-H\left(\begin{array}{c}
\left(t^{\prime}-t\right)-\sum_{t^{\prime \prime} \in T} N_{i, l, t^{\prime \prime}, t^{\prime \prime}+1} \\
t \leq t^{\prime \prime}<t^{\prime}
\end{array}\right) \forall i \in I_{\mathrm{st}}, l \in L_{i}, t \in T, t^{\prime} \in T, t^{\prime}>t, t \neq|T|
\end{aligned}
$$


If a sequence of storage tasks associated with a material resource $r$ of lot $l$ has extended the product lifetime $\sigma_{i l}$ a binary variable $S_{i, l, t, t^{\prime}}$ is activated (Eqs. (41) and (42)). To assure the feasibility, it is assumed that the shelf-life related to any intermediate/product is never greater that the considered time horizon $H$.

$$
\begin{aligned}
& x_{i, l, t, t^{\prime}}-\sigma_{i, l} \leq H S_{i, l, t, t^{\prime}} \quad \forall i \in I_{\mathrm{st}}, l \in L_{i}, t \in T, t^{\prime} \in T, t^{\prime}>t, t \neq|T| \\
& x_{i, l, t, t^{\prime}}-\sigma_{i l} \geq H\left(S_{i, l, t, t^{\prime}}-1\right) \quad \forall i \in I_{\mathrm{st}}, l \in L_{i}, t \in T, t^{\prime} \in T, t^{\prime}>t, t \neq|T|
\end{aligned}
$$

Eqs. (39) and (40) guarantee that, for an interval [ $\left.t, t^{\prime}\right]$, if the stored resource $r$ of lot $l$ has extended the product lifetime $\left(S_{i, l, t, t^{\prime}}=1\right)$, the variable $W_{r l t}$ determines the respective amount sent to waste disposal $\left(R_{r, l, t^{\prime}-1}\right) . V_{\mathrm{st}}^{\max }$ is a big-M scalar related to the overall maximum available storage capacity. Finally, Eqs. (43) and (46) assure that variable $W_{r, l, t}$ take value zero for all the remaining cases where no shelf life restrains are applied.

$$
\begin{aligned}
& W_{r, l, t^{\prime}} \geq R_{r, l, t^{\prime}-1}-V_{\mathrm{st}}^{\max }\left(1-\sum_{i \in I_{r}^{s t}} S_{i, l, t, t^{\prime}}\right) \quad \forall r \in M / \mathrm{RM}, l \in L_{r}, t \in T, t<|T|-1, t^{\prime}>\mathrm{t}+1 \\
& W_{r, l, t^{\prime}} \leq R_{r, l, t^{\prime}-1}+V_{\mathrm{st}}^{\max }\left(1-\sum_{i \in I_{r}^{\mathrm{st}}} S_{i, l, t, t^{\prime}}\right) \quad \forall r \in M / \mathrm{RM}, l \in L_{r}, t \in T, t<|T|-1, t^{\prime}>t+1 \\
& W_{r, l, t^{\prime}} \leq V_{\mathrm{st}}^{\max } \sum_{i \in I_{r}^{\mathrm{st}}} S_{i, l, t, t^{\prime}} \quad \forall r \in M / \mathrm{RM}, l \in L_{r}, t \in T, t<|T|-1, t^{\prime}>t \\
& \sum_{t \in T} W_{r, l, t}=0 \quad \forall r \notin M / \mathrm{RM}, l \in L_{r}
\end{aligned}
$$

\subsubsection{Objective function}

Regarding the objective function, the profit maximisation is given by Eq. (47). The first term represents the income result from sales $\left(v_{r}\right)$ minus the production costs $\left(c_{r}\right)$, the second and third term represent the operating costs due to an active storage request for the excess amount of resource $r$ at each time event $\left(c_{r}^{s t}\right)$ and the cost of intermediate changeover/setup-up procedures required in-between different tasks $i$ and $i^{\prime}\left(c_{i, i^{\prime}}^{\mathrm{ch}}\right)$, and the last terms are related to the disposal cost $\left(c_{r}^{d}\right)$ of extended shelflife products and backlog penalties cost $\left(c_{r}^{u}\right)$ of unfulfilled demand. All costs are in "relative monetary units" (rmu).

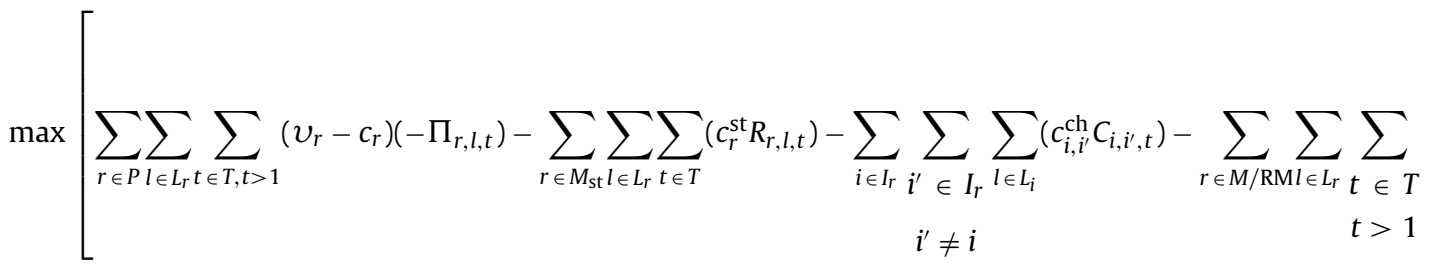

$$
\begin{aligned}
& \left.c_{r}^{d} W_{r, l, t}-\sum_{r \in P} \sum_{l \in L_{r}} \sum_{\substack{t \in T \\
t>1}} c_{r}^{u} \Pi_{r, l, t}^{u}\right]
\end{aligned}
$$

\section{Illustrative examples}

In this section, considering the mathematical formulation composed by Eqs. (3)-(47), three planning/scheduling optimisation problems in a biopharmaceutical industrial plant are presented to explore the different model features. The examples were adapted from the operational parameters provided by Lakhdar et al. (2005), which is based on real industrial data and covering the most common aspects of biopharmaceuticals' production. All models were implemented using GAMS (GAMS 24.4.3 WIN VS8 x86) and solved with CPLEX running on an Intel Xeon ES-2660 v3 at $2.60 \mathrm{GHz}$ with $64 \mathrm{~GB}$ of RAM.

\subsection{Example I}

The first example considers a mid-term planning problem in the biopharmaceutical industry adapted from Lakhdar et al. (2005): a two-stages facility composed by two upstream fermentation suites [J1 \& J2] and two downstream purification suites [J3 \& J4] per stage, to manufacture products P1, P2 and P3 in a continuous production mode (Fig. 5). The demand profile considers a total of 34 batches to be delivered in a set of campaign-lots in five delivery dates for a 360 days production horizon $H$ (Table 1 ), assuming that late deliveries are penalised. For the profit maximisation, the problem considers: the total sales and the costs of manufacturing, storage, changeover/setup and disposal. The time related to sequence independent changeover/setup procedures was determined based in the product lead time provided in the example by Lakhdar et al. (2005). The remaining data used in the formulation, including manufacturing rate, minimum 


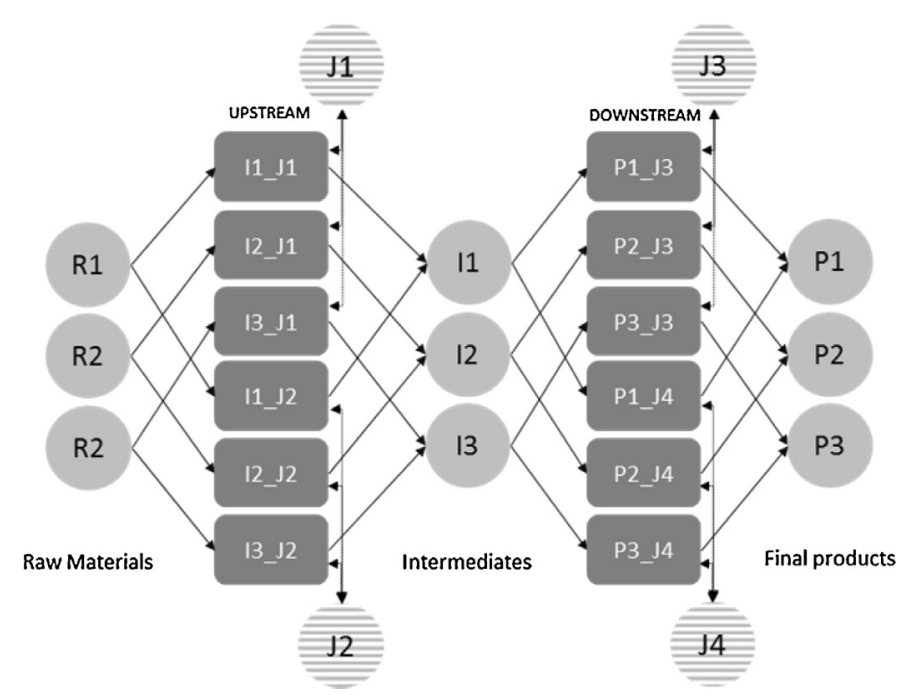

Fig. 5. RTN production layout for Example I.

Table 1

Demand profile for Example I.

\begin{tabular}{|c|c|c|c|c|c|c|}
\hline \multirow[t]{2}{*}{ Product } & \multirow[t]{2}{*}{ Total demand (batch) } & \multicolumn{5}{|c|}{ Due dates (days) } \\
\hline & & $\mathrm{d} 1(120)$ & $\mathrm{d} 2(180)$ & d3 (240) & $\mathrm{d} 4(300)$ & d5 (360) \\
\hline P1 & 12 & & & 6 & & 6 \\
\hline P2 & 6 & & 6 & & & \\
\hline P3 & 16 & 8 & & & 8 & \\
\hline
\end{tabular}

Table 2a

Main parameters for Example I.

\begin{tabular}{|c|c|c|c|c|c|c|c|c|c|}
\hline & \multirow{2}{*}{$\begin{array}{l}\text { Manufacturing } \\
\text { rate-max } \\
\text { (batch/day) }\end{array}$} & \multicolumn{3}{|c|}{$\begin{array}{l}\text { Sequence-dep. } \\
\text { changeover time (days) }\end{array}$} & \multirow{2}{*}{$\begin{array}{l}\text { Minimum } \\
\text { campaign } \\
\text { length (days) }\end{array}$} & \multirow[t]{2}{*}{$\begin{array}{l}\text { Stored material } \\
\text { lifetime (days) }\end{array}$} & \multirow[t]{2}{*}{$\begin{array}{l}\text { Storage cost } \\
\text { (rmu/batch.event) }\end{array}$} & \multirow{2}{*}{$\begin{array}{l}\text { Waste disposal } \\
\text { cost } \\
\text { (rmu/batch) }\end{array}$} & \multirow[t]{2}{*}{$\begin{array}{l}\text { Changeover } \\
\text { cost (rmu) }\end{array}$} \\
\hline & & I1 & $\mathrm{I} 2$ & I3 & & & & & \\
\hline I1 & 0.05 & (10) & 10 & 10 & 20 & 60 & 5 & 5 & 1 \\
\hline I2 & 0.045 & 10 & (10) & 10 & 22 & 60 & 5 & 5 & 1 \\
\hline \multirow[t]{3}{*}{ I3 } & 0.08 & 10 & 10 & (10) & 12.5 & 60 & 5 & 5 & 1 \\
\hline & $\begin{array}{l}\text { Manufacturing } \\
\text { rate-max } \\
\text { (batch/dav) }\end{array}$ & \multicolumn{3}{|c|}{$\begin{array}{l}\text { Sequence-dep. } \\
\text { changeover time (days) }\end{array}$} & $\begin{array}{l}\text { Minimum } \\
\text { campaign } \\
\text { length (days) }\end{array}$ & & & & \\
\hline & & $\overline{\mathrm{P} 1}$ & P2 & $\overline{\mathrm{P} 3}$ & & & & & \\
\hline P1 & 0.1 & (30) & 32 & 24.5 & 10 & 180 & 1 & 5 & 1 \\
\hline P2 & 0.1 & 30 & (32) & 24.5 & 10 & 180 & 1 & 5 & 1 \\
\hline P3 & 0.1 & 30 & 32 & $(24.5)$ & 10 & 180 & 1 & 5 & 1 \\
\hline
\end{tabular}

Table 2b

Main parameters for Example I.

\begin{tabular}{|c|c|c|c|c|}
\hline & Manufacturing cost (2 steps) (rmu/batch) & Sales price (rmu/batch) & Lateness penalty (rmu/batch.event) & Production factor $\lambda_{i, r}$ \\
\hline P1 & 4 & 20 & 20 & 1 \\
\hline P2 & 4 & 20 & 20 & 1 \\
\hline P3 & 4 & 20 & 20 & 1 \\
\hline
\end{tabular}

campaign length and product lifetime, is summarised in Tables 2a and 2b. The term "batch" in the data parameter, in order to reproduce the original problem statement, was assumed to correspond to a fix undisclosed amount due to confidentiality reasons. To comply with processes requirements, the blending of lots of intermediates is allowed (Eq. (15)), the changeovers in downstream units are set to occur only at the beginning of the time interval (Eqs. (29) and (31)), the given production rates correspond to equipment maximum specs, and unlimited storage capacity is assumed with no zero wait policies. Furthermore, in order to compare the the results obtained by Lakhdar et al. (2005), the scheduled batch tasks are set to last only one time interval ( $\Delta t=1$ ) and restrictive storage constraints given by Eqs. (36) and (37) were disregarded. 
Table 3

GAMS model results.

\begin{tabular}{|c|c|c|c|c|c|c|}
\hline Event points & Discrete variables & Total variables & Equations & Objective MILP & $\mathrm{CPU}(\mathrm{s})$ & Optimality gap (\%) \\
\hline 6 & 3931 & 5638 & 6649 & 278 & 1.8 & 0.0 \\
\hline 7 & 5237 & 7361 & 8898 & 513 & 27.8 & 0.0 \\
\hline 8 & 6723 & 9300 & 11459 & 513 & 390.1 & 0.0 \\
\hline 9 & 8389 & 11455 & 14332 & 511 & 2142.5 & 0.0 \\
\hline
\end{tabular}

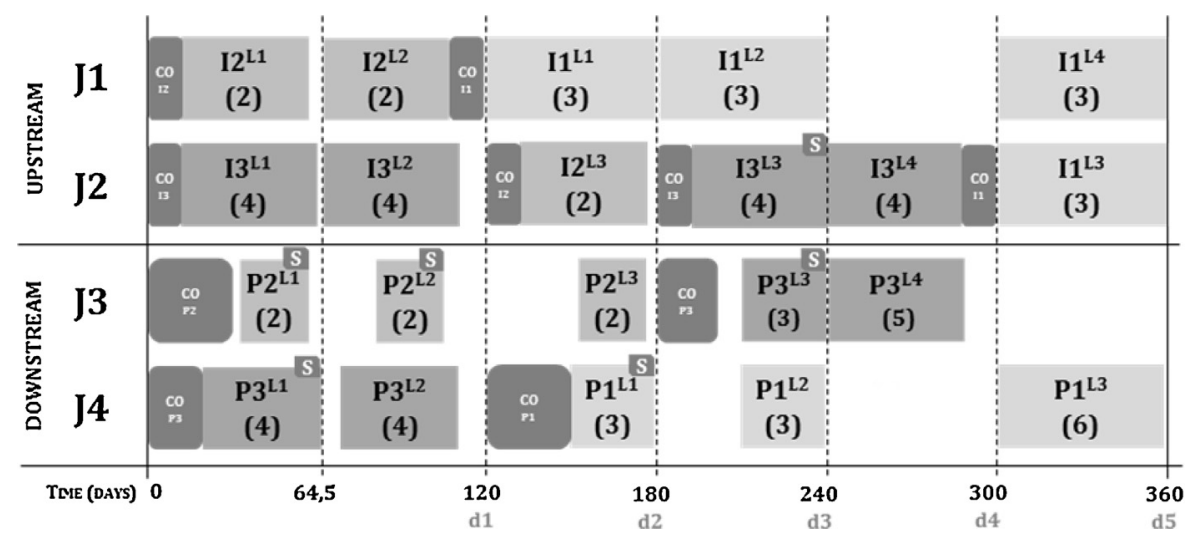

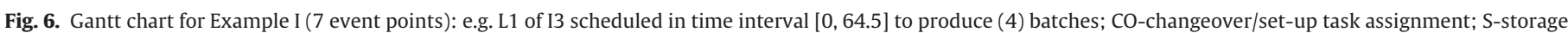
allocation; d\#-due date. (solution: $513 \mathrm{rmu}$ ).

\subsubsection{Example I results}

The computational results for the optimal schedule are presented in Table 3 . Since in a continuous time formulation the number of time events must be defined based on the analysis of the problem, the first attempt considered 6 event points. This is the minimum allowed by the model, since there are 5 delivery time events plus the initial time point $t_{0}$. Although, it was insufficient for the total on-time fulfillment of the plan (profit $278 \mathrm{rmu}$, mostly penalised by late deliveries), but with 7 event points the demand is totally satisfied without penalties or waste disposal costs, for an optimal profit of $513 \mathrm{rmu}$. The results for 8 and 9 event points are shown but without any solution improvement, which is coherent with the proposed stopping criteria to deliver the solution when the increment in the number of event points is not accompanied by an increment in the objective function. In practice, since Eq. (10) does not allow the repetition of absolute time events, the solution is forced to create additional time intervals which can incur in profit penalties.

Considering the 7 event points solution, the Gantt chart of Fig. 6 presents the optimal sequencing and allocation of the different processing tasks in each of the processing suites, identifying: lot number and integer campaign size of each intermediate/product manufacturing task (amount in brackets); the changeover/set up requirements when different products are processed in the same unit (identified by [CO] symbol); and the products' storage allocation (identified by [S] symbol). Due to different processing rates, the tool developed to generate the Gantt chart considered that the end of each downstream task is never lower than the end of precursor upstream task. The results exhibit, for example, that 4 lots of $\mathrm{I} 1$ and 3 lots of $\mathrm{P} 1$ are produced: lot $\mathrm{L} 3$ of $\mathrm{P} 1\left(\mathrm{P} 1{ }^{\mathrm{L} 3}\right)$ is scheduled in unit [J4] during the time event interval $[300,360]$ by the blending of lots L3 and L4 of I1. Also, a single lot L1 of I1 scheduled to unit [J1] generates a single lot of P1 ${ }^{\mathrm{L} 1}$ in unit [J4] during time event interval $[120,180]$. In this last case, the amount of lot L1 of P1 produced is being stored till the third delivery date (d3) on the 240th day. Six storage tasks are active in the planning horizon to store 5 lots of final products (until the due dates are met) and 1 lot of intermediary product I3, which can be detailed in the production inventory profile in Fig. 7 . These charts also verify that, on the 240 th day, lot $\mathrm{P} 1^{\mathrm{L} 1}$ (stored since the previous interval) and the produced lot $\mathrm{P} 1^{\mathrm{L} 2}$ totals 6 bathes delivered (indicated with a triangle symbol) corresponding to the due date $\mathrm{d} 3$ demand. Recall that in this example, each storage task is only active for the following time interval when the material resource excess is verified, according to Eq. (35). Regarding equipment changeover tasks, ten transfer cleaning/set-up procedures are required. Following the original problem statement by Lakhdar et al. (2005), the same set-up time was assigned for each first campaign scheduled. As noted, the changeover time for the upstream units is allocated as suitable to either the beginning or end of the time slots, allowing the improvement of the duration/size of production tasks scheduled. Considering the utilisation rate of each equipment suite for the given horizon, it is verified that the upstream process is the limiting step due to its higher processing times, obtaining a 80\% and $96 \%$ utilisation rate in J1 and J2, respectively, while downstream suites $\mathrm{J} 3$ and $\mathrm{J} 4$ present $55 \%$ and $71 \%$ rate, respectively.

\subsubsection{Results comparison with Lakhdar et al. (2005) model}

The mid-term planning problem here presented was originally addressed by Lakhdar et al. (2005), which proposed a MILP model with a 60 days discrete-time formulation to determine the optimal production schedule assuming a continuous processing upstream/downstream flow. The Gantt chart of Fig. 8 and the production inventory profile in Fig. 9 display the results obtained. In Table 4 the GAMS results are compared with our model solution with 7 event points in three distinct scenarios.

The extent in number of variables and equations differ widely when comparing the discrete time model with our proposed continuoustime formulation, mostly due to RTN framework and the additional features included, such as the lot tracking not addressed by Lakhdar et al. (2005). For a simplified comparison exercise of the two models, in Table 4 is also shown the solution statistics if the lot features were disregarded (constraints [20-22]), suggesting a significant reduction in computational complexity. Nevertheless, our solution schedule is able to provide an improved objective profit in $+23 \mathrm{rmu}(4.7 \%)$. The profit result of the discrete time model is mostly penalised by the unfulfilled delivery of 1 batch of P1 due at the 240th day (Fig. 9). And although with one less changeover/set-up tasks scheduled, it presents 
10
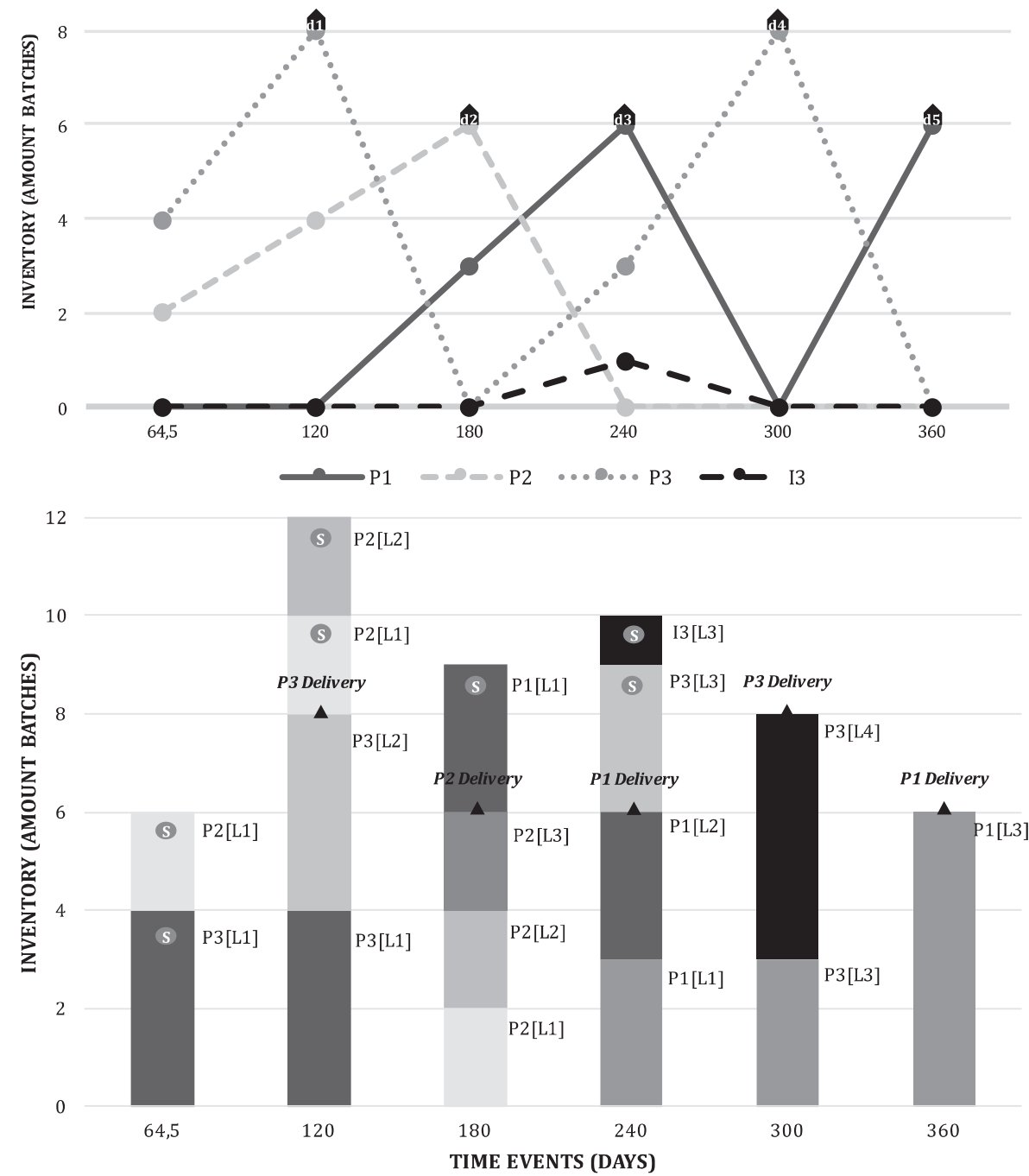

Fig. 7. Material resources inventory profile for Example I [S] and [triangle] symbols identify, respectively, the storage allocation and the product amounts deliveries at due dates- d\#).

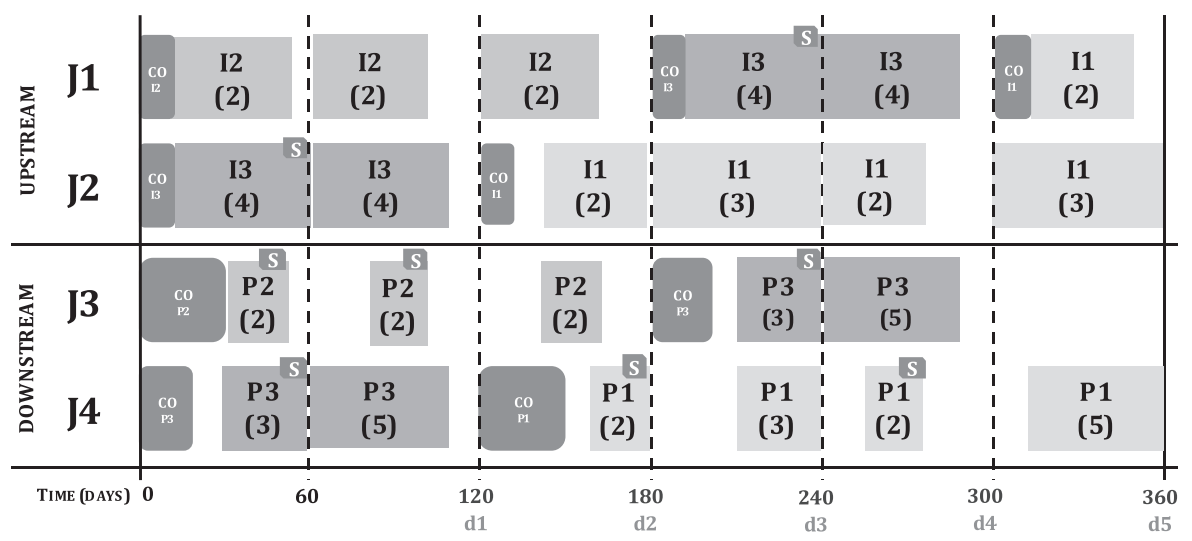

Fig. 8. Gantt chart for Example I using Lakhdar et al. (2005) discrete time formulation (solution: $490 \mathrm{rmu}$ ).

additional storage costs of intermediate materials ( $\mathrm{I} 3$ in the first and fourth time interval). Must be refereed that the discrete-time model presents a different estimate of the storage costs, but since both solutions show the same number of time intervals it can be disregarded. Indeed, the solution improvement is verified because the continuous-time model flexes the duration of the first time interval to 64.5 days (the remaining events were allocated to due dates), while the discrete-time model fixes all intervals length in 60 days, a time difference sufficient enough that allows to manufacture 4 batches of P3 in the first time slot to match demand on time. It was also verified that this 
10
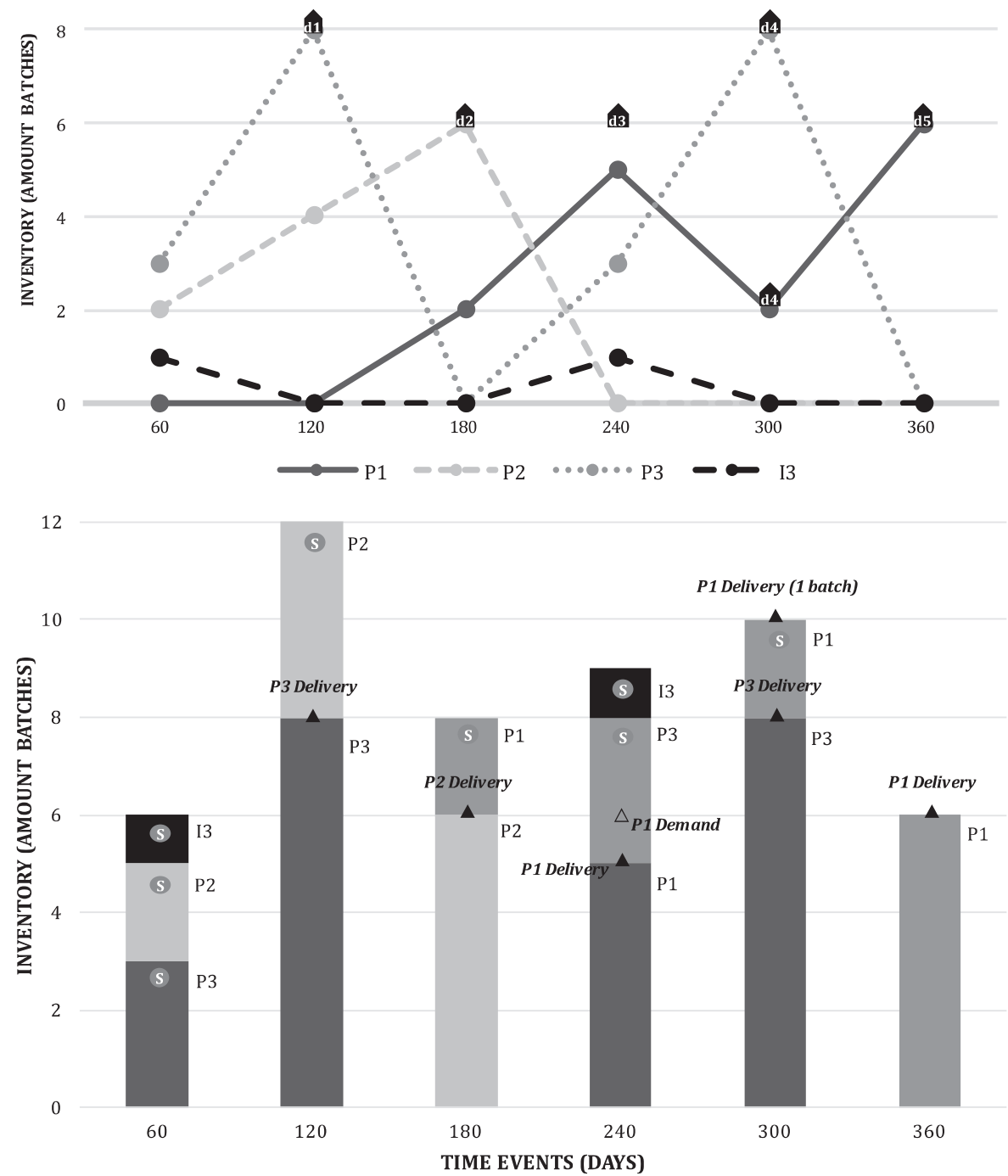

Fig. 9. Material resources inventory for Example I using Lakhdar et al. (2005) discrete time formulation.

Table 4

GAMS model results for Example I.

\begin{tabular}{|c|c|c|c|c|c|c|}
\hline & Discrete variables & Total variables & Equations & Objective MILP & $\mathrm{CPU}(\mathrm{s})$ & Optimality gap (\%) \\
\hline Lakhdar et al. (2005) & 252 & 457 & 499 & 490 & 0.3 & 0.0 \\
\hline Proposed model-7 time events & 5237 & 7361 & 8898 & 513 & 27.8 & 0.0 \\
\hline $\begin{array}{l}\text { Proposed model for a single lot } \\
\text { index }-7 \text { time events }\end{array}$ & 539 & 1601 & 2163 & 513 & 2.2 & 0.0 \\
\hline $\begin{array}{l}\text { Proposed model using a continuous } \\
\text { batch-extent variable- }-7 \text { time events }\end{array}$ & 1709 & 7361 & 8898 & 519 & 46.9 & 0.0 \\
\hline
\end{tabular}

model presents some limitations in the assignment of changeovers (demanding that at most one product undergoes manufacturing in any given intermediate time period) or in the implementation of a shorter discretization of the time horizon.

It must be noted that, to follow the original scheduling problem statement and perform a fair comparison with the results presented by Lakhdar et al. (2005), the extent variable $\xi_{\text {iltt' }}$ (that determines the amount of batches produced in each scheduled campaign-task) was also set as an integer variable. As expected, if the scheduling problem unrestraint the campaign-extent size to any non-integer number which, it can generate additional savings in the optimal profit by reducing the costs of stored products. Fig. 10 illustrates this aspect, depicting a similar schedule solution but now the optimal profit increases to $519 \mathrm{rmu}$, mainly due to avoid the storage costs of intermediary I3. For example, the schedule of non-integer task campaigns allows that the amount stored of final products in $t=120$ days is equal to 3,7 batches (P2[L1\&L2]), while in the previous solution the stored amounts is 4 batches. 


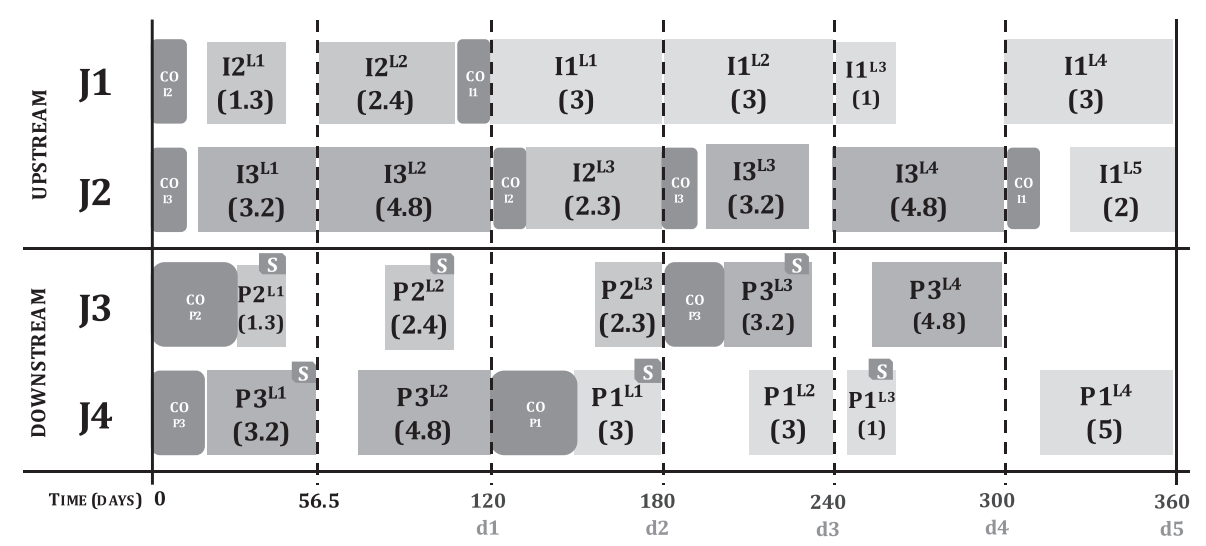

Fig. 10. Gantt chart for Example I (7 event points) considering the extent variable $\xi_{\text {iltt' }}$ as a positive continuous variable (solution: 519 rmu).

Table 5

Demand profile for Example II.

\begin{tabular}{|c|c|c|c|c|}
\hline \multirow[t]{2}{*}{ Product } & \multirow[t]{2}{*}{ Total demand $(\mathrm{kg})$} & \multicolumn{3}{|c|}{ Due dates (days) } \\
\hline & & $\mathrm{d} 1(100)$ & $\mathrm{d} 2(180)$ & d3 (240) \\
\hline P1 & 6 & & & 6 \\
\hline P2 & 6 & & 6 & \\
\hline
\end{tabular}

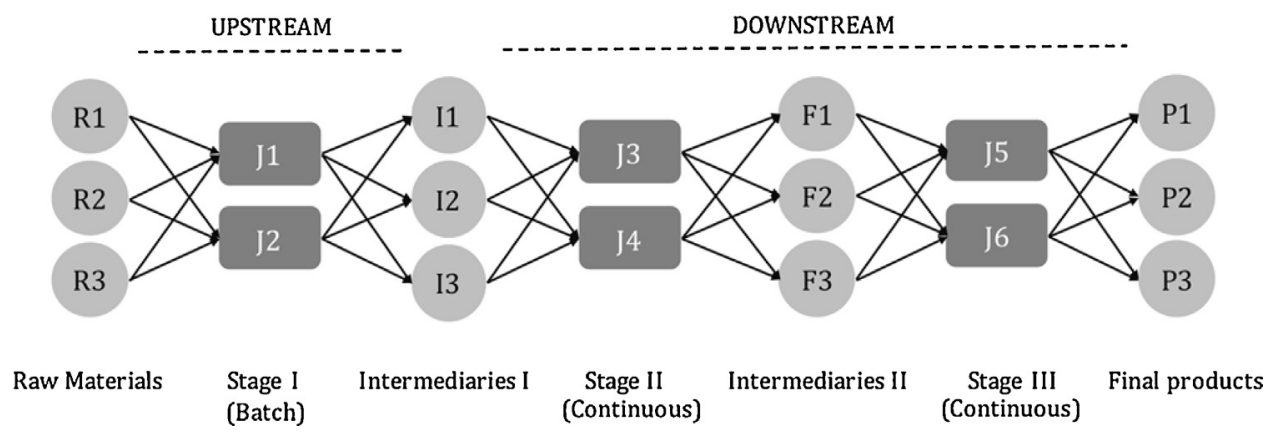

Fig. 11. Production layout for example II.

\subsection{Example II}

To further demonstrate the model features, in this second example we are considering an alternative campaign planning problem for a shorter demand period of 240 days with three delivery dates, $6 \mathrm{~kg}$ of P1, $6 \mathrm{~kg}$ of P2 and $8 \mathrm{~kg}$ of P3, shown in Table 5. As displayed in Fig. 11, the hybrid production process is now composed by one upstream stage that operates in a batch mode (Stage I), followed by two downstream continuous process steps, an ultrafiltration (Stage II) and a chromatography (Stage III) step, each stage composed by two identical processing suites. The operational data, presented in Tables $6 \mathrm{a}$ and $6 \mathrm{~b}$, were adapted from provided industrial information. For this case, different sequence-dependent changeover times were defined for Stage 2 units for the process combinations possible (F1 $\Leftrightarrow \mathrm{F} 2 \Leftrightarrow \mathrm{F} 3$ ) and batch tasks are subject to equipment volume limitations. The same premises stated in Example I are followed, with the exception that the extent task variable $\xi_{\text {iltt' }}$ is not limited to integer amounts and all restrictions for storage tasks are applied (Eqs. (36) and (37)), which tightens the formulation for the lifetime limitations of biomaterials. Regarding the blending of lots of intermediaries, two situations are going to be explored, considering for the initial approach that all is allowed. Finally, based on a preliminary analysis of processing times, the maximum duration of all batch tasks was set to two time intervals $(\Delta t=2)$.

\subsubsection{Example II results}

Table 7 reveals the results of the solution iteration for a set of time events, which the optimal solution is verified with 7 events for a profit of $268 \mathrm{rmu}$, since with 8 events no solution improvement is verified. In the first iteration with 4 time events (three due dates plus the initial $t=0$ ), the profit solution is highly penalised with unfulfilled demand costs, seeing that the short number of time intervals is even more noticeable with this example, since a sequence of a batch and a continuous task requires, at least, two time intervals to accomplish the production of a certain amount. Since tasks in stage I are processed in batch mode, the produced intermediaries are only made available for the following stage after the end of the task, while continuous tasks of stages II and III occur simultaneously. The optimal planning is presented in the Gantt chart of Fig. 12, outlining the sequencing, allocation, storage and changeover requirements for the campaign lots in each of the processing suites. Twelve equipment changeover/setup tasks are required and only one storage task is active for P1. Fig. 13 resumes the production profile of Stage I intermediaries and final products, fulfilling the total demand on predefined due dates. It can be verified that the optimal solution considers that campaigns $\mathrm{I} 2^{\mathrm{L} 1}, \mathrm{I} 2^{\mathrm{L} 2}$ and $\mathrm{I} 1^{\mathrm{L} 1}$ are scheduled to widen for two consecutive time intervals, a 
Table 6a

Main parameters for Example II.

\begin{tabular}{|c|c|c|c|c|c|c|c|c|c|}
\hline & \multirow[t]{2}{*}{$\begin{array}{l}\text { Manufacturing } \\
\text { time }-\beta \text { (day/kg) }\end{array}$} & \multicolumn{3}{|c|}{$\begin{array}{l}\text { Sequence-dep. } \\
\text { changeover time } \\
\text { (days) }\end{array}$} & \multirow[t]{2}{*}{$\begin{array}{l}\text { Equipment } \\
\text { capacity [max] (kg) }\end{array}$} & \multirow[t]{2}{*}{$\begin{array}{l}\text { Stored material } \\
\text { lifetime (days) }\end{array}$} & \multirow[t]{2}{*}{$\begin{array}{l}\text { Storage cost } \\
\text { (rmu/kg.event) }\end{array}$} & \multirow[t]{2}{*}{$\begin{array}{l}\text { Waste disposal cost } \\
(\mathrm{rmu} / \mathrm{kg})\end{array}$} & \multirow[t]{2}{*}{$\begin{array}{l}\text { Changeover cost } \\
\text { (rmu) }\end{array}$} \\
\hline & & I1 & I2 & I3 & & & & & \\
\hline I1 & 18 & $(10)$ & 10 & 10 & 5 & 60 & 5 & 5 & 1 \\
\hline I2 & 20 & 10 & (10) & 10 & 5 & 60 & 5 & 5 & 1 \\
\hline \multirow[t]{3}{*}{ I3 } & 12.5 & 10 & 10 & $(10)$ & 5 & 60 & 5 & 5 & 1 \\
\hline & $\begin{array}{l}\text { Manufacturing } \\
\text { rate-max (kg/day) }\end{array}$ & \multicolumn{3}{|c|}{$\begin{array}{l}\text { Sequence-dep. } \\
\text { changeover time } \\
\text { (days) }\end{array}$} & \multirow[t]{2}{*}{$\begin{array}{l}\text { Minimum } \\
\text { campaign length } \\
\text { (days) }\end{array}$} & & & & \\
\hline & & $\mathrm{F} 1$ & $\mathrm{~F} 2$ & F3 & & & & & \\
\hline $\mathrm{F} 1$ & 0.22 & (10) & 35 & 20 & 4.5 & 120 & 1 & 5 & 1 \\
\hline $\mathrm{F} 2$ & 0.2 & 16 & (10) & 30 & 5 & 120 & 1 & 5 & 1 \\
\hline \multirow[t]{3}{*}{ F3 } & 0.25 & 18 & 22 & (10) & 4 & 120 & 1 & 5 & 1 \\
\hline & $\begin{array}{l}\text { Manufacturing } \\
\text { rate-max (kg/day) }\end{array}$ & \multicolumn{3}{|c|}{$\begin{array}{l}\text { Sequence-dep. } \\
\text { changeover time } \\
\text { (days) }\end{array}$} & \multirow[t]{2}{*}{$\begin{array}{l}\text { Minimum } \\
\text { campaign length } \\
\text { (days) }\end{array}$} & & & & \\
\hline & & P1 & P2 & P3 & & & & & \\
\hline P1 & 0.2 & (30) & 32 & 24.5 & 5 & 120 & 1 & 5 & 1 \\
\hline P2 & 0.2 & 30 & (32) & 24.5 & 5 & 120 & 1 & 5 & 1 \\
\hline P3 & 0.2 & 30 & 32 & $(24.5)$ & 5 & 120 & 1 & 5 & 1 \\
\hline
\end{tabular}

Table 6b

Main parameters for Example II.

\begin{tabular}{|c|c|c|c|c|}
\hline & Manufacturing cost (3 steps) (rmu/kg) & Sales price (rmu/kg) & Lateness penalty (rmu/kg.event) & Production factor $\lambda_{i, r}$ \\
\hline P1 & 6 & 20 & 20 & 1 \\
\hline P2 & 6 & 20 & 20 & 1 \\
\hline P3 & 6 & 20 & 20 & 1 \\
\hline
\end{tabular}

Table 7

GAMS model results for Example II.

\begin{tabular}{|c|c|c|c|c|c|c|}
\hline Event points & Discrete variables & Total variables & Equations & Objective MILP & $\mathrm{CPU}(\mathrm{s})$ & Optimality gap (\%) \\
\hline 4 & 5087 & 4210 & 5087 & -121.1 & 0.5 & 0.0 \\
\hline 5 & 1961 & 6059 & 7735 & 122.8 & 3.2 & 0.0 \\
\hline 6 & 2565 & 8196 & 10851 & 214.6 & 39.8 & 0.0 \\
\hline 7 & 3223 & 10621 & 14435 & 268.0 & 101.8 & 0.0 \\
\hline 8 & 3935 & 13334 & 18487 & 268.0 & 1509.2 & 0.0 \\
\hline 9 & 4701 & 16335 & 23007 & 267.0 & 3600.0 & 1.0 \\
\hline
\end{tabular}

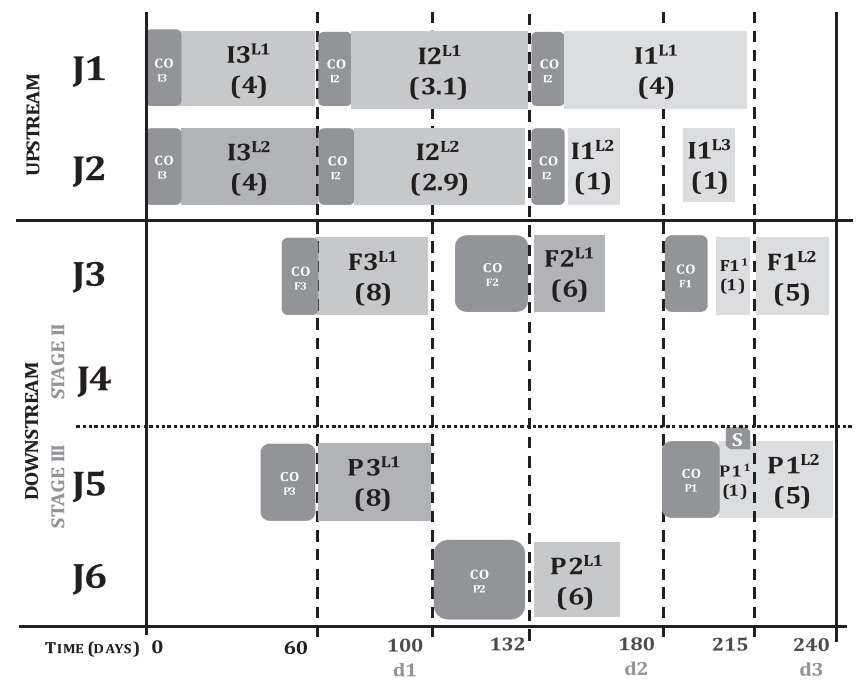

Fig. 12. Gantt chart for Example II with 7 event points (solution: $268 \mathrm{rmu}$ ). 


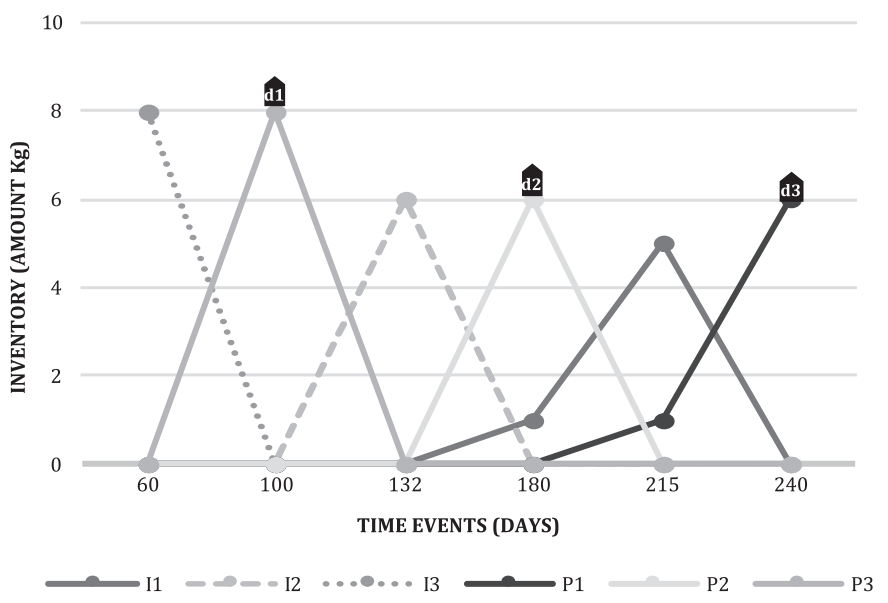

Fig. 13. Material resources inventory for Example II.

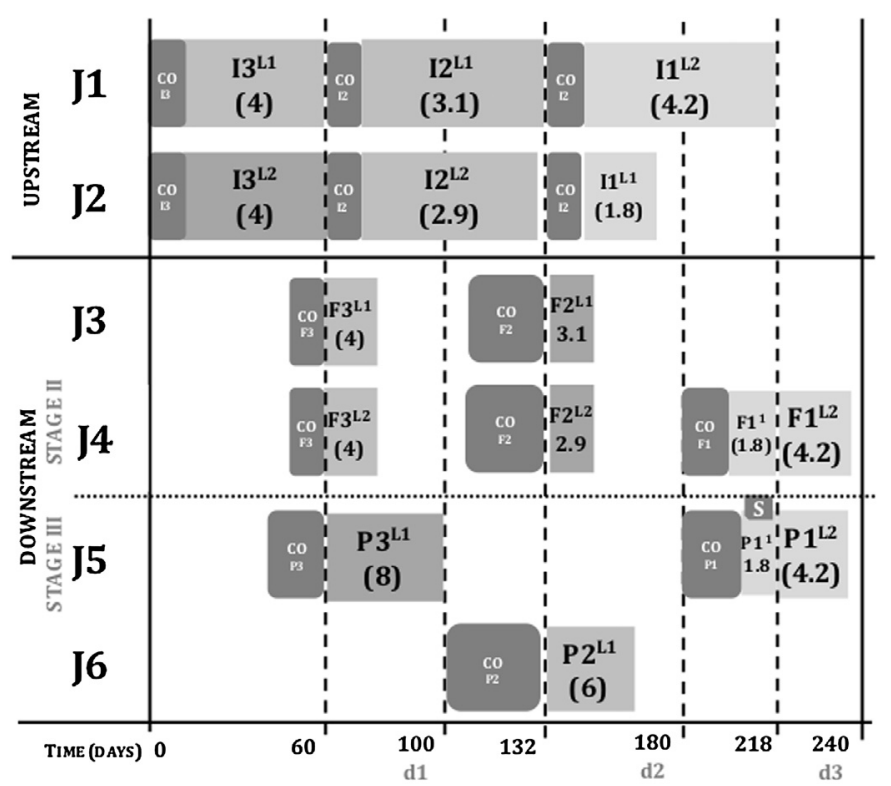

Fig. 14. Gantt chart for Example II with 7 event points, assuming no blending of Stage I intermediaries' lots ( solution 265.3 rmu, $0 \%$ optimality gap, after 466 s).

model feature that improves the flexibility of the solution results, while preserving computational hindrance, with relevance for this type of single-time grid horizon approaches.

It can be also verified in Fig. 12 that suite J4 is not used, since the production rates in Stage II are sufficiently fast to process both Stage I lots of all intermediaries in the same unit. However, this is only possible because the blending/splitting of lots are allowed. Therefore, if we consider the case subject to regulatory purposes that the blending of Stage I intermediaries is forbidden (still allowed for intermediaries II), the new solution for 7 time events given in Figs. 14 and 15. It can be verified that unit J4 is now required and it allows to follow the track record of the different lots throughout the units allocation of the production process. The optimal profit solution is now $265.3 \mathrm{rmu}$, penalised by the additional two changeover/set-up requirements and additional storage costs with $\mathrm{P} 1^{\mathrm{L} 1}$ at 218 days. As previously mentioned, the importance of regulatory requirements is strictly important in all aspects of pharmaceutical manufacturing, where the relevance of lot traceability plays an important role to comply with an optimal scheduling solution. As reference, in these examples it was assumed that the model freely assigns the number of sequential lots and sizes, but the formulation also allows the cases where a specific set of lot sizes are requested (Eq. (23a)).

\subsection{Example III}

In this third example, we address a more detailed process layout for the manufacturing of three biopharmaceutical products P1, P2 and P3, by disaggregating the upstream/downstream production suites into five main operations. The production sequence, as displayed in Fig. 16, is composed by two batch stages for upstream processing (cell fermentation and clarification), and for downstream processing, two stages operate in a continuous mode while the last in batch mode (centrifugation, ultrafiltration and chromatography). The problem considers 9 equipment units, and task-unit suitability is verified for intermediaries of P1 on the first upstream stage, with I1 only able to be processed in unit $\mathrm{J} 1$ due to regulatory policies. In Table 8 the demand profile with 3 intermediate due dates is defined, and the operational data, presented in Tables 9a and 9b, considers different selling prices for the three final products. The same premises stated in Example II are followed, except that the maximum duration of all batch tasks was assumed to last one interval in this case $(\Delta t=1)$. 


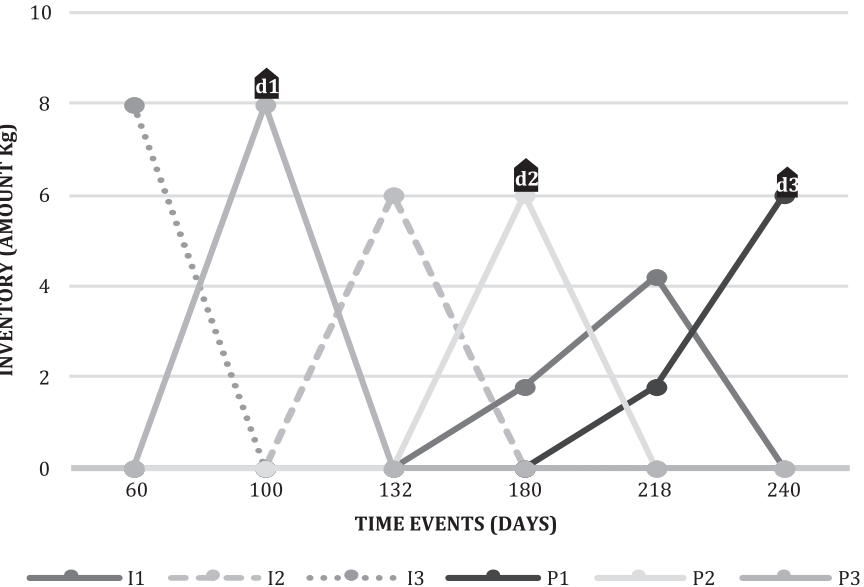

Fig. 15. Material resources inventory for Example II, assuming no blending of Stage I intermediaries' lots.

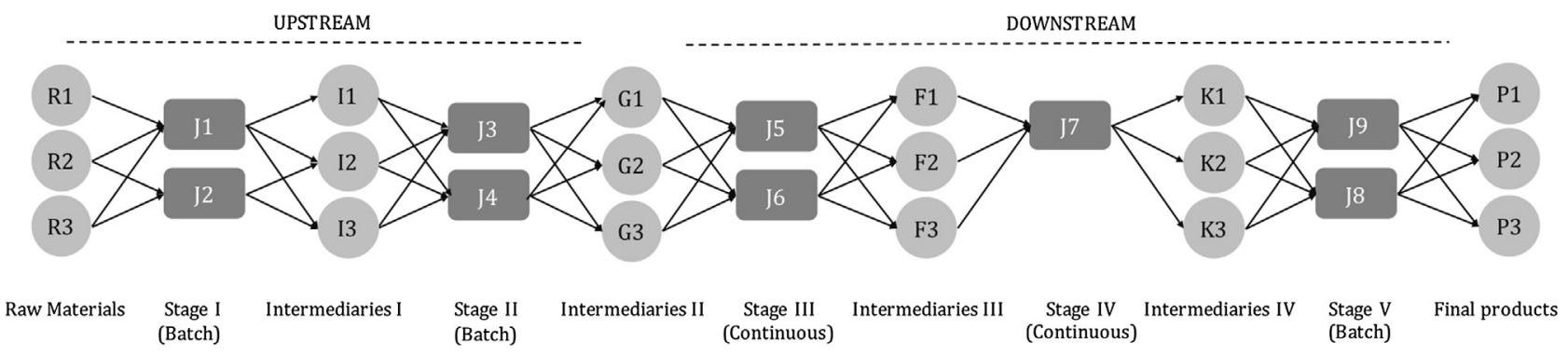

Fig. 16. Production layout for example III.

Table 8

Demand profile for Example III.

\begin{tabular}{|c|c|c|c|c|}
\hline \multirow[t]{2}{*}{ Product } & \multirow[t]{2}{*}{ Total demand (kg) } & \multicolumn{3}{|c|}{ Due dates (days) } \\
\hline & & $\mathrm{d} 1(80)$ & $\mathrm{d} 2(110)$ & d3 (150) \\
\hline P1 & 2 & & 2 & \\
\hline $\mathrm{P} 2$ & 2 & & & 2 \\
\hline P3 & 2 & 2 & & \\
\hline
\end{tabular}

\subsubsection{Example III results}

With this industrial problem, the purpose was to discuss the model performance considering a production layout with 5 process steps, acknowledging the generality of the model formulation with its different model features. In Table 10 is shown the solution iteration for the set of time events, reaching the optimal planning solution of $106 \mathrm{rmu}$ with 8 time events, presented in the Gantt chart of Fig. 17. It shows the size/duration, sequencing, allocation, storage and changeover requirements for the campaign lots in each processing unit, with the flow sequence of batch and continuous tasks. Although, it requires additional time events to accomplish a complete production sequence and, for this reason, the first results of the solution iteration in Table 10 are penalised. The profit results for 9 and 10 time events were also penalised due to extra storage costs. In the Gantt chart of Fig. 17 is it possible to follow the assignment of the different scheduled tasks to each processing unit/stage, able to comply with the deliver of two batches of P3, P1 and P2 on the 80th, 110th 150th day, respectively. It was assumed that the blending of lots in upstream stages was not allowed due to regulatory policies, but it can be verified at stage III, where two lots of F1 originate one of K1,or as well the splitting of one lot of $\mathrm{K} 2$ to originate two lots of P2 at the final stage. The flexibility to schedule the changeover/set-up time and the blending of lots has proven to allow an improved allocation of the different tasks to the planning horizon. However, it was also noted the computational complexity increase with the problem data set, which should be a criterion in our research as a requirement to provide an operational decision-support tool for industrial environments.

\section{Conclusions}

In this work a MILP formulation, based on a RTN continuous-time single time-grid formulation, was developed to solve the campaign planning/scheduling problems of biopharmaceutical processes. Acknowledging a fairly unexplored topic, the work was focused in addressing specific constraints of these biochemical processes not yet combined, which included the modelling of batch and/or continuous process steps, multiple intermediate deliveries, sequence dependent operations, storage of products regarding shelf-life limitations, and the track-control of the production lots for regulatory policies. The developed model was applied to three examples with different production layouts: the first example considered a mid-term planning problem representing the two main stages (upstream/downstream) of biopharmaceutical processes; the second example discussed additional model features onto a hybrid production process with three batch and continuous stages; and the third example extended the production layout considering the five main processing steps. Based 
Table 9a

Main parameters for Example III.

\begin{tabular}{|c|c|c|c|c|c|c|c|c|c|}
\hline & \multirow[t]{2}{*}{$\begin{array}{l}\text { Manufacturing } \\
\text { time- } \beta \text { (day/kg) }\end{array}$} & \multicolumn{3}{|c|}{$\begin{array}{l}\text { Sequence-dep. } \\
\text { changeover time } \\
\text { (days) }\end{array}$} & \multirow[t]{2}{*}{$\begin{array}{l}\text { Equipment } \\
\text { capacity [max] } \\
(\mathrm{kg})\end{array}$} & \multirow[t]{2}{*}{$\begin{array}{l}\text { Stored material } \\
\text { lifetime (days) }\end{array}$} & \multirow[t]{2}{*}{$\begin{array}{l}\text { Storage cost } \\
\text { (rmu/ kg.event) }\end{array}$} & \multirow[t]{2}{*}{$\begin{array}{l}\text { Waste disposal } \\
\text { cost (rmu/ kg) }\end{array}$} & \multirow[t]{2}{*}{$\begin{array}{l}\text { Changeover } \\
\text { cost (rmu) }\end{array}$} \\
\hline & & I1 & I2 & I3 & & & & & \\
\hline I1 & 10 & (10) & 10 & 10 & 5 & 60 & 5 & 5 & 1 \\
\hline I2 & 12 & 10 & (10) & 10 & 5 & 60 & 5 & 5 & 1 \\
\hline \multirow[t]{3}{*}{ I3 } & 6.5 & 10 & 10 & (10) & 5 & 60 & 5 & 5 & 1 \\
\hline & $\begin{array}{l}\text { Manufacturing } \\
\text { time- } \beta \text { (day/kg) }\end{array}$ & \multicolumn{3}{|c|}{$\begin{array}{l}\text { Sequence-dep. } \\
\text { changeover time } \\
\text { (days) }\end{array}$} & \multirow[t]{2}{*}{$\begin{array}{l}\text { Equipment } \\
\text { capacity [max] } \\
(\mathrm{kg})\end{array}$} & & & & \\
\hline & & G1 & G2 & G3 & & & & & \\
\hline G1 & 5 & (20) & 3 & 20 & 4 & 120 & 5 & 5 & 1 \\
\hline G2 & 4 & 16 & (20) & 35 & 4 & 120 & 5 & 5 & 1 \\
\hline \multirow[t]{3}{*}{ G3 } & 4.5 & 18 & 22 & (20) & 4 & 120 & 5 & 5 & 1 \\
\hline & $\begin{array}{l}\text { Manufacturing } \\
\text { rate-max (kg/day) }\end{array}$ & \multicolumn{3}{|c|}{$\begin{array}{l}\text { Sequence-dep. } \\
\text { changeover time } \\
\text { (days) }\end{array}$} & \multirow[t]{2}{*}{$\begin{array}{l}\text { Minimum } \\
\text { campaign } \\
\text { length (days) }\end{array}$} & & & & \\
\hline & & $\mathrm{F} 1$ & $\mathrm{~F} 2$ & F3 & & & & & \\
\hline $\mathrm{F} 1$ & 0.2 & (15) & 15 & 15 & 5 & 120 & 1 & 5 & 1 \\
\hline F2 & 0.25 & 15 & (15) & 15 & 5 & 120 & 1 & 5 & 1 \\
\hline \multirow[t]{3}{*}{ F3 } & 0.28 & 15 & 15 & (15) & 5 & 120 & 1 & 5 & 1 \\
\hline & $\begin{array}{l}\text { Manufacturing } \\
\text { rate-max (kg/day) }\end{array}$ & \multicolumn{3}{|c|}{$\begin{array}{l}\text { Sequence-dep. } \\
\text { changeover time } \\
\text { (days) }\end{array}$} & \multirow[t]{2}{*}{$\begin{array}{l}\text { Minimum } \\
\text { campaign } \\
\text { length (days) }\end{array}$} & & & & \\
\hline & & K1 & K2 & K3 & & & & & \\
\hline K1 & 0.32 & (10) & 18 & 18 & 5 & 120 & 1 & 5 & 1 \\
\hline K2 & 0.3 & 18 & (10) & 18 & 5 & 120 & 1 & 5 & 1 \\
\hline \multirow[t]{3}{*}{ K3 } & 0.28 & 18 & 18 & (10) & 5 & 120 & 1 & 5 & 1 \\
\hline & $\begin{array}{l}\text { Manufacturing } \\
\text { time- } \beta \text { (day/kg) }\end{array}$ & \multicolumn{3}{|c|}{$\begin{array}{l}\text { Sequence-dep. } \\
\text { changeover time } \\
\text { (days) }\end{array}$} & \multirow[t]{2}{*}{$\begin{array}{l}\text { Equipment } \\
\text { capacity [max] } \\
(\mathrm{kg})\end{array}$} & & & & \\
\hline & & P1 & P2 & Р3 & & & & & \\
\hline P1 & 6 & (30) & 32 & 24.5 & 5 & 120 & 1 & 5 & 1 \\
\hline P2 & 8 & 30 & (32) & 24.5 & 5 & 120 & 1 & 5 & 1 \\
\hline P3 & 4.5 & 30 & 32 & $(24.5)$ & 5 & 120 & 1 & 5 & 1 \\
\hline
\end{tabular}

Table 9b

Main parameters for Example III.

\begin{tabular}{|c|c|c|c|c|}
\hline & Manufacturing cost (5 steps) (rmu/kg) & Sales price (rmu/kg) & Lateness penalty (rmu/kg.event) & Production factor $\lambda_{i, r}$ \\
\hline P1 & 10 & 30 & 20 & 1 \\
\hline P2 & 10 & 38 & 20 & 1 \\
\hline P3 & 10 & 25 & 20 & 1 \\
\hline
\end{tabular}

Table 10

GAMS model results for Example III.

\begin{tabular}{|c|c|c|c|c|c|c|}
\hline Event points & Discrete variables & Total variables & Equations & Objective MILP & $\mathrm{CPU}(\mathrm{s})$ & Optimality gap (\%) \\
\hline 4 & 3318 & 7413 & 7877 & -249 & 0.3 & 0.0 \\
\hline 5 & 4443 & 12023 & 11483 & -152 & 1.4 & 0.0 \\
\hline 6 & 5658 & 16947 & 16263 & -41 & 4.9 & 0.0 \\
\hline 7 & 6963 & 17727 & 22649 & 15 & 82.1 & 0.0 \\
\hline 8 & 8358 & 22017 & 29129 & 106 & 95.2 & 0.0 \\
\hline 9 & 9843 & 26733 & 36387 & 103 & 563.2 & 0.0 \\
\hline 10 & 11418 & 31875 & 44423 & 101 & 1792.5 & 0.0 \\
\hline
\end{tabular}

on different industrial data sets and demand profiles, the model was able to solve the optimal schedule for each problem, providing the sequencing and allocation of the different processing units, the track record of campaign-lot quantities for each intermediate/product, the sequence-dependent changeover requirements and storage allocations. The results of the first example were compared with a discrete-time model, originally presented by Lakhdar et al. (2005), and discussed the advantages of the proposed continuous-time formulation in the duration/extent of scheduled campaign-tasks in order to fulfill the production demand. 


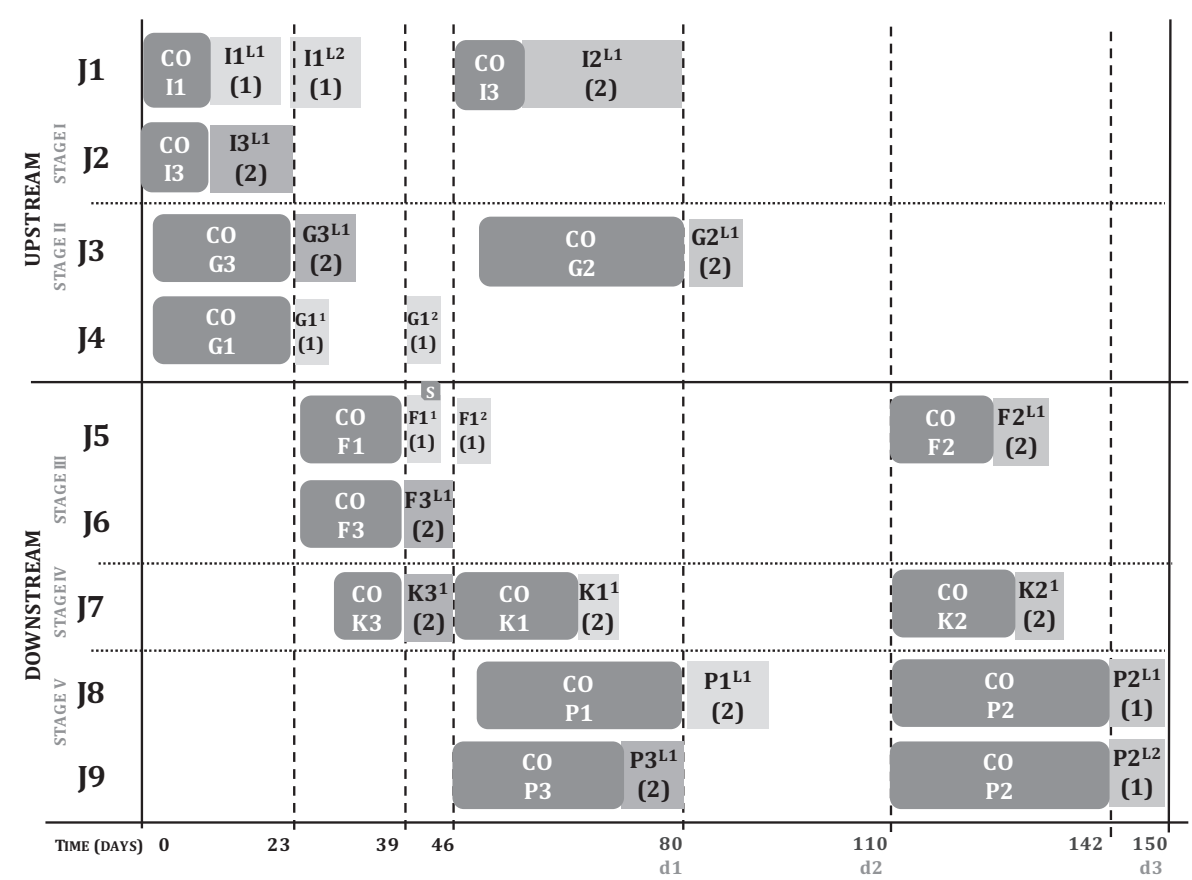

Fig. 17. Gantt chart for Example III with 8 event points, assuming no blending allowed of upstream stages intermediaries' lots (solution: 106 rmu).

As main conclusion, this work resumes a generic formulation to address the main campaign planning/scheduling challenges of biopharmaceutical processes. The RTN continuous time model was proven to be effective to solve the proposed industrial problems, particularly sensitive to changes in the tasks duration. Further research work will address alternative time-grid formulations to enhance computational performance into the complexity of real biopharmaceutical production processes, understanding the diverse model approaches and scalability. Some modelling aspects to overcome in future works are associated with the robustness of the storage features between batch and continuous tasks, the related control of shelf-life time constrains of stored materials, and the integration of operational parameters uncertainty to replicate real process variability.

\section{Acknowledgement}

The authors would like to acknowledge the financial support of Fundação para a Ciência e Tecnologia under the grant SFRH/BD/51594/2011 and project NORTE-01-0145-FEDER-000020 financed by NORTE 2020, under the PORTUGAL 2020 Partnership Agreement and through the European Regional Development Fund (ERDF).

\section{References}

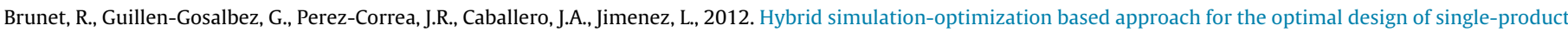
biotechnological processes. Comput. Chem. Eng. 37, 125-135.

Castro, P.M., 2010. Optimal scheduling of pipeline systems with a resource-task network continuous-time formulation. Ind. Eng. Chem. Res. 49, 11491-11505.

Castro, P.M., Barbosa-Povoa, A.P., Matos, H.A., Novais, A.Q., 2004. Simple continuous-time formulation for short-term scheduling of batch and continuous processes. Ind. Eng. Chem. Res. 43, 105-118.

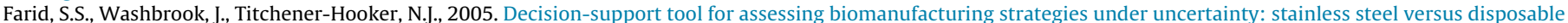
equipment for clinical trial material preparation. Biotechnol. Prog. 21, 486-497.

Farid, S.S., Washbrook, J., Titchener-Hooker, N.J., 2007. Modelling biopharmaceutical manufacture: design and implementation of SimBiopharma. Comput. Chem. Eng. 31, $1141-1158$.

Harjunkoski, I., Maravelias, C.T., Bongers, P., Castro, P.M., Engell, S., Grossmann, I.E., Hooker, J., Méndez, C., Sand, G., Wassick, J., 2014. Scope for industrial applications of production scheduling models and solution methods. Comput. Chem. Eng. 62, 161-193.

Junker, B.H., Wang, H.Y., 2006. Bioprocess monitoring and computer control: key roots of the current PAT initiative. Biotechnol. Bioeng. 95, $226-261$.

Kabra, S., Shaik, M.A., Rathore, A.S., 2013. Multi-period scheduling of a multi-stage multi-product bio-pharmaceutical process. Comput. Chem. Eng. 57, 95-103.

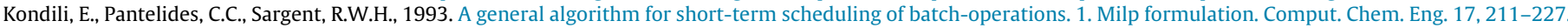

Lakhdar, K., Papageorgiou, L.G., 2008. An iterative mixed integer optimisation approach for medium term planning of biopharmaceutical manufacture under uncertainty. Chem. Eng. Res. Des. 86, 259-267.

Lakhdar, K., Savery, J., Papageorgiou, L.G., Farid, S.S., 2007. Multiobjective long-term planning of biopharmaceutical manufacturing facilities. Biotechnol. Prog. 23, 1383-1393.

Lakhdar, K., Zhou, Y., Savery, J., Titchener-Hooker, N.J., Papageorgiou, L.G., 2005. Medium term planning of biopharmaceutical manufacture using mathematical programming. Biotechnol. Prog. 21, 1478-1489.

Leachman, R.C., Johnston, L., Li, S., Shen, Z.-J., 2014. An automated planning engine for biopharmaceutical production. Eur. J. Operational Res. 238 , 327-338.

Liu, S., Simaria, A.S., Farid, S.S., Papageorgiou, L.G., 2015. Mathematical programming approaches for downstream processing optimisation of biopharmaceuticals. Chem. Eng. Res. Des. 94, 18-31.

Liu, S., Yahia, A., Papageorgiou, L.G., 2014. Optimal production and maintenance planning of biopharmaceutical manufacturing under performance decay. Ind. Eng. Chem. Res. 53, 17075-17091.

Maravelias, C.T., Grossmann, I.E., 2003. New general continuous-time state-task network formulation for short-term scheduling of multipurpose batch plants. Ind. Eng. Chem. Res, 42, 3056-3074.

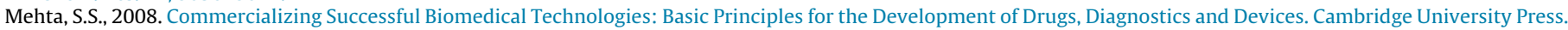

Méndez, C.A., Cerdá, J., Grossmann, I.E., Harjunkoski, I., Fahl, M., 2006. State-of-the-art review of optimization methods for short-term scheduling of batch processes. Comput. Chem. Eng. 30, 913-946. 
Moniz, S., Barbosa-Povoa, A.P., DE Sousa, J.P., 2013. New general discrete-time scheduling model for multipurpose batch plants. Ind. Eng. Chem. Res. 52, $17206-17220$.

Moniz, S., Barbosa-Póvoa, A.P., DE Sousa, J.P., 2014a. Simultaneous regular and non-regular production scheduling of multipurpose batch plants: a real chemical-pharmaceutical case study. Comput. Chem. Eng. 67, 83-102.

Moniz, S., Barbosa-Póvoa, A.P., DE Sousa, J.P., Duarte, P., 2014b. Solution methodology for scheduling problems in batch plants. Ind. Eng. Chem. Res. 53, 19265-19281.

Pantelides, C.C., 1994. Unified frameworks for optimal process planning and scheduling. In: Proceedings on the Second Conference on Foundations of Computer Aided Operations, New York. Cache Publications.

Rajapakse, A., Titchener-Hooker, N.J., Farid, S.S., 2005. Modelling of the biopharmaceutical drug development pathway and portfolio management. Comput. Chem. Eng. 29, $1357-1368$.

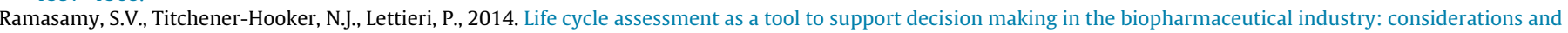
challenges. Food Bioprod. Process. 94, 297-305.

Schilling, G., Pantelides, C.C., 1996. A simple continuous-time process scheduling formulation and a novel solution algorithm. Comput. Chem. Eng. 20, S1221-S1226.

Shah, N., 2004. Pharmaceutical supply chains: key issues and strategies for optimisation. Comput. Chem. Eng. 28, 929-941.

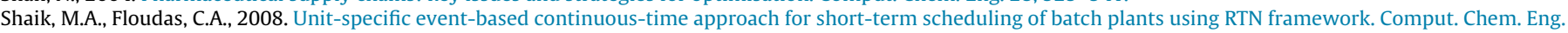
$32,260-274$.

Shaik, M.A., Floudas, C.A., 2009. Novel unified modeling approach for short-term scheduling. Ind. Eng. Chem. Res. 48, 2947-2964.

Shaik, M.A., Dhakre, A., Rathore, A.S., Patil, N., 2014. Capacity optimization and scheduling of a multiproduct manufacturing facility for biotech products. Biotechnol. Prog. 30 (5), 1221-1230

Siganporia, C.C., Ghosh, S., Daszkowski, T., Papageorgiou, L.G., Farid, S.S., 2014. Capacity planning for batch and perfusion bioprocesses across multiple biopharmaceutical facilities. Biotechnol. Prog. 30 (3), 594-606

Simaria, A.S., Turner, R., Farid, S.S., 2012. A multi-level meta-heuristic algorithm for the optimisation of antibody purification processes. Biochem. Eng. J. 69 , $144-154$.

Vieira, M., Pinto-Varela, T., Barbosa-Povoa, A.P., 2015. Planning and scheduling in the biopharmaceutical industry: an overview. In: Thokozani Majozi, E.R.S., Jui-Yuan, Lee (Eds.), Synthesis, Design, and Resource Optimization in Batch Chemical Plants. CRC Press.

Walsh, G., 2010. Biopharmaceutical benchmarks 2010. Nat. Biotechnol. 28, 917-924. 